\title{
Arrhythmogenic Mechanisms in Heart Failure: Linking $\beta$-Adrenergic Stimulation, Stretch, and Calcium
}

\author{
Daniel M. Johnson ${ }^{1 *}$ and Gudrun Antoons ${ }^{2 *}$ \\ ' Department of Cardiothoracic Surgery, Cardiovascular Research Institute Maastricht, Maastricht University, Maastricht, \\ Netherlands, ${ }^{2}$ Department of Physiology, Cardiovascular Research Institute Maastricht, Maastricht University, Maastricht, \\ Netherlands
}

\section{OPEN ACCESS}

Edited by:

Marcel van der Heyden, University Medical Center Utrecht,

Netherlands

Reviewed by: Rachel C. Myles,

University of Glasgow, United Kingdom

Marina Cerrone,

New York University, United States

*Correspondence:

Daniel M. Johnson danjohnsonmaastricht@gmail.com

Gudrun Antoons

g.antoons@maastrichtuniversity.nl

Specialty section:

This article was submitted to

Cardiac Electrophysiology,

a section of the journal

Frontiers in Physiology

Received: 08 August 2018 Accepted: 25 September 2018

Published: 16 October 2018

Citation:

Johnson DM and Antoons $G$ (2018) Arrhythmogenic Mechanisms in Heart Failure: Linking $\beta$-Adrenergic

Stimulation, Stretch, and Calcium.

Front. Physiol. 9:1453.

doi: 10.3389/fphys.2018.01453
Heart failure (HF) is associated with elevated sympathetic tone and mechanical load. Both systems activate signaling transduction pathways that increase cardiac output, but eventually become part of the disease process itself leading to further worsening of cardiac function. These alterations can adversely contribute to electrical instability, at least in part due to the modulation of $\mathrm{Ca}^{2+}$ handling at the level of the single cardiac myocyte. The major aim of this review is to provide a definitive overview of the links and cross talk between $\beta$-adrenergic stimulation, mechanical load, and arrhythmogenesis in the setting of HF. We will initially review the role of $\mathrm{Ca}^{2+}$ in the induction of both early and delayed afterdepolarizations, the role that $\beta$-adrenergic stimulation plays in the initiation of these and how the propensity for these may be altered in HF. We will then go onto reviewing the current data with regards to the link between mechanical load and afterdepolarizations, the associated mechano-sensitivity of the ryanodine receptor and other stretch activated channels that may be associated with HF-associated arrhythmias. Furthermore, we will discuss how alterations in local $\mathrm{Ca}^{2+}$ microdomains during the remodeling process associated the HF may contribute to the increased disposition for $\beta$-adrenergic or stretch induced arrhythmogenic triggers. Finally, the potential mechanisms linking $\beta$-adrenergic stimulation and mechanical stretch will be clarified, with the aim of finding common modalities of arrhythmogenesis that could be targeted by novel therapeutic agents in the setting of HF.

Keywords: heart failure, myocytes, calcium, sympathetic stimulation, stretch, ryanodine, microdomains

Abbreviations: $\beta$-AR, $\beta$-adrenergic receptor; AC, adenyl cyclase; AP, action potential; BVR, beat-to-beat variability of repolarization; CaMKII, $\mathrm{Ca}^{2+} /$ calmodulin dependent protein kinase II; cAMP, cyclic adenosine $3^{\prime}, 5^{\prime}$-monophosphate; Casq2, cardiac calsequestrin; CICR, calcium induced calcium release; DAD, delayed afterdepolarization; EAD, early afterdepolarization; ECC, excitation contraction coupling; Epac, exchange protein activated by cAMP; HF, heart failure; $\mathrm{I}_{\mathrm{TI}}$, transient inward current; LTCC, L-type calcium channel; LVAD, left ventricular assist device; NCX, sodium/calcium exchanger; NO, nitric oxide; NOS, nitric oxide synthase; NOX2, NADPH oxidase 2; PI3K, phosphoinositide 3-kinase; PKA, protein kinase A; PLB, phospholamban; ROS, reactive oxygen species; RyR, ryanodine receptor; SACNS, stretch activated non-selective cation current; SERCA, SR $\mathrm{Ca}^{2+}$-ATPase; SR, sarcoplasmic reticulum; INaL, late sodium current. 


\section{INTRODUCTION}

Heart failure is a complex clinical syndrome with many contributory factors including ischemia, congenital heart disease, and pulmonary hypertension. HF can be defined as HF with preserved ejection fraction ( $\mathrm{HFpEF})$, when diastolic dysfunction plays a major role, or $\mathrm{HF}$ with reduced ejection fraction (HFrEF). HF with reduced ejection fraction has been associated with elevated sympathetic tone and mechanical load (Lohse et al., 2003). Both systems activate signaling transduction pathways that increase cardiac output, but adversely contribute to electrical instability, at least partially via modulation of $\mathrm{Ca}^{2+}$ handling.

The first documentation of alterations in the sympathetic signaling in chronic HF was when a decrease in concentrations of the sympathetic nervous neurotransmitter, norepinephrine, was shown in the failing human heart (Chidsey et al., 1963). Since that time, there has been accumulating evidence that the sympathetic nervous system plays a considerable role in HF (Port and Bristow, 2001) and this is highlighted by the continued use of $\beta$-receptor blockers as a favorable pharmacological treatment of HF (Waagstein et al., 1993; Ponikowski et al., 2016).

The hyperadrenergic state is in large part caused by an imbalance of autonomic reflex responses to early alterations in cardiac and peripheral hemodynamics (Toschi-Dias et al., 2017). In HF, vagal control by the baroreceptor reflex is reduced (Eckberg et al., 1971), while sympatho-excitatory reflexes are augmented, including the cardiac sympathetic afferent reflex (Wang and Zucker, 1996). The cardiacspecific reflex originates in the ventricle and is activated by elevated filling pressures (Malliani et al., 1973; Wang and Zucker, 1996), creating a positive feedback loop as its activation causes excessive sympathetic outflow to the heart and arteries (Chen et al., 2015). In turn, the heart readapts its systolic and diastolic force to the adrenergic-mediated increases in hemodynamic load via intrinsic autoregulatory mechanisms (Neves et al., 2015). Thus, adrenergic and hemodynamic regulatory systems tightly interact via a complex interplay of feedback mechanisms at the local and systemic level that are initially compensatory, but ultimately pathological.

Arrhythmias are a major cause of mortality in HF patients, and sudden cardiac death has previously been linked with a higher NYHA class (Saxon et al., 2006; Santangeli et al., 2017). Furthermore, in a recent study, ventricular arrhythmias were seen in up to $45 \%$ of patients who had received a LVAD (Garan et al., 2013). Although over the last decades remarkable advances have been made in terms of our understanding of risk factors and the efficacy of device therapy the underlying mechanisms responsible for arrhythmia induction and sudden cardiac death in this population remain elusive, and this is largely down to the complexity of the disease.

In this review, we will focus on the roles that altered sympathetic stimulation as well as mechanics may have on arrhythmogenic phenotype in patients with HF with reduced ejection fraction, concentrating on alterations of $\mathrm{Ca}^{2+}$ dynamics, $\beta$-adrenergic stimulation and stretch at the level of the single cardiac myocyte. It is hoped that information gained in this field will ultimately lead to novel strategies that could improve our therapeutic arsenal against HF.

\section{BASIC PRINCIPLES OF CALCIUM- DEPENDENT ARRHYTHMOGENESIS- AFTERDEPOLARIZATIONS}

Before discussing arrhythmogenic mechanisms in HF we need to understand the basic mechanisms of arrhythmogenesis and the link to $\mathrm{Ca}^{2+}$.

Afterdepolarizations are thought to be one of the major mechanisms driving arrhythmogenesis in multiple pathophysiologies and we will concentrate on these in this review (Figure 1). These oscillations in the membrane potential can lead to either triggered activity and/or functional block which may encourage re-entry circuits (Wit and Rosen, 1983). These phenomena can be detected at multiple levels, ranging from the single cardiac myocyte to the tissue and can even be observed in the intact heart when monophasic APs are recorded (Priori et al., 1990). They are defined as depolarizations of the cardiac AP that can occur in phases 2, 3, or 4 of the AP (Cranefield, 1977). When they occur in phase 4 of the AP they are called DADs whereas if they occur earlier on the AP then they are termed EADs.

There is now a general consensus that DADs are a result of a $\mathrm{I}_{\mathrm{TI}}$ activated by intracellular $\mathrm{Ca}^{2+}$ (Marban et al., 1986). This $\mathrm{I}_{\mathrm{TI}}$ was originally described by Lederer and Tsien (1976) as a result of digitalis-induced arrhythmias and was later shown to be mainly due to activation of the electrogenic $\mathrm{Na}^{+}-\mathrm{Ca}^{2+}$ exchanger (NCX), while the $\mathrm{Ca}^{2+}$-activated $\mathrm{Cl}^{-}$ current $\left(\mathrm{ICl}_{\mathrm{Ca}}\right)$ appears to contribute in some species (Fedida et al., 1987; Zygmunt et al., 1998). Interestingly a study from Verkerk et al. (2001) showed that $\mathrm{I}_{\mathrm{TI}}$ in failing human cardiac myocytes was as a result of NCX alone. In addition to the potential of DADs to induce arrhythmias via triggered activity or functional block, recent work has also highlighted the potential of DADs to increase beat-to-beat variability of repolarization (BVR) which may also contribute to the arrhythmogenic nature of these afterdepolarizations (Johnson et al., 2013). The $\mathrm{Ca}^{2+}$ that activates these arrhythmogenic currents originate from the SR and is released via diastolic release events (Venetucci et al., 2008). For these reasons, when the SR is overloaded with $\mathrm{Ca}^{2+}$, for example during intense $\beta$-adrenergic stimulation, the chance of spontaneous $\mathrm{Ca}^{2+}$ release is increased as is the likelihood for DADs (Yamada and Corr, 1992).

Mechanisms underlying EADs are much less clear cut however, and remain a topic of much debate. Early evidence suggested EADs were caused as a result of reactivation of $\mathrm{I}_{\mathrm{CaL}}$ due to the prolonged plateau phase of the AP (January and Riddle, 1989; Zeng and Rudy, 1995). However, there is other experimental evidence that suggests that EADs may also be caused as a result of $\mathrm{I}_{\mathrm{TI}}$ activation by intracellular $\mathrm{Ca}^{2+}$, especially under conditions of $\mathrm{Ca}^{2+}$ overload (Priori et al., 


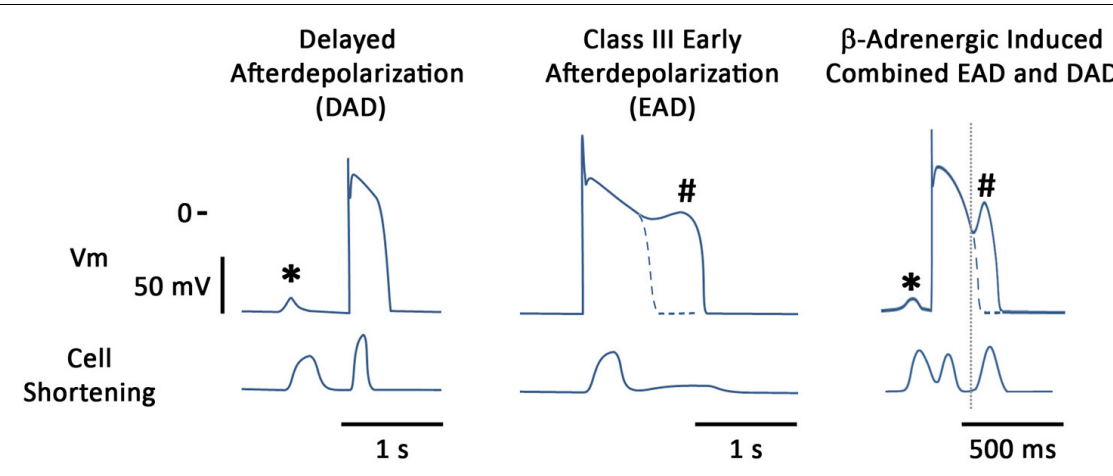

FIGURE 1 | Stylized examples of afterdepolarizations occurring in the single canine myocyte. Figure shows both membrane potentials and contraction for each situation. (Left) DAD $\left(^{*}\right)$ induced by the $\beta$-adrenergic agonist isoproterenol (ISO); (Middle) illustrates an EAD (\#) induced by augmentation of the late sodium current, using ATX-II; (Right) illustrates that under certain conditions both types of afterdepolarizations can be seen in the same action potential. In this particular example, blockade of the potassium current, $\mathrm{I}_{\mathrm{Ks}}$, together with $\beta$-adrenergic stimulation are the proarrhythmic treatment and it can be seen that an early aftercontraction initiates prior to the upstroke of the EAD.

1990; Volders et al., 1997, 2000). Either way, it appears that EADs are modulated by systolic release of $\mathrm{Ca}^{2+}$ during the $\mathrm{AP}$ and are regulated by feedback on $\mathrm{Ca}^{2+}$ sensitive ion currents.

The link of afterdepolarizations at the single myocyte level to arrhythmogenesis at the whole heart level is extremely complex and incompletely understood. In the intact heart, myocytes are electrically coupled to each other, meaning that the membrane voltage is governed by not just one cell but multiple cells. Furthermore, the contribution of one afterdepolarization occurring in one cell (the source) will likely be negated by the neighboring cells not experiencing afterdepolarizations (the sink). Elegant work from the laboratory of James Weiss has investigated this phenomenon and has shown that chaotic EADs are able to synchronize globally when the tissue is smaller than a critical size. However, when the tissue is large enough, complete synchronization of EADs can no longer occur and this results in regions of partial synchronization that shift in time and space, that can act as foci for arrhythmia (Sato et al., 2009). Furthermore, work from the same group also estimated that the number of local myocyte DADs needed to be synchronized to induce a premature beat would be very large, however, this could be reduced structural and electrical remodeling (Xie et al., 2010). Finally, a recent study from the Bers' lab has also highlighted that in HF there is a much higher density of ' $\mathrm{Ca}^{2+}$ asynchronous' myocytes that are poorly coupled to the surrounding myocardium. These poorly coupled myocytes may also contribute to initiating triggered activity (Lang et al., 2017).

Over recent years it has become apparent that $\mathrm{Ca}^{2+}$ control of repolarization, and therefore also of arrhythmogenesis is more of a local rather than a global phenomenon. Both functional and structural microdomains dictate local $\mathrm{Ca}^{2+}$ concentrations, gradients and effector proteins. As these domains appear to be affected in HF, especially when we consider $\beta$-adrenergic stimulation and stretch we must also consider how this local control occurs.

\section{LOCAL CONTROL OF $\mathrm{Ca}^{2+}$ RELEASE AT THE DYAD}

In cardiac myocytes, $\mathrm{Ca}^{2+}$ is centrally involved in many processes including excitability, contraction, and regulation of gene expression. Such diversity of functional roles postulates the existence of dedicated microdomains in which $\mathrm{Ca}^{2+}$ signals are generated independently of cytosolic $\mathrm{Ca}^{2+}$ concentrations and sensed by macromolecular signaling components localized to these microdomains. Besides a functional component, $\mathrm{Ca}^{2+}$ microdomains are often physically delimited by specialized membrane structures and subcellular compartments. Specialized structures include dyadic junctions between transverse membrane invaginations (T-tubules) and SR, sarcolemmal domains outside dyads such as lipid rafts and caveolae, and intracellular structures such as tethered junctions between SR and mitochondria. Interestingly, compartmentalization of proteins that generate or regulate microdomain $\mathrm{Ca}^{2+}$ signaling is dynamic, often as a cause or consequence of disease. For example, the LTCC, or nNOS coupled to RyR, can translocate from the dyad to the sarcolemma which alters their function, presumably by coupling to different signaling complexes (Sanchez-Alonso et al., 2016; Carnicer et al., 2017).

\section{Structural Organization}

In the dyad, RyR in the SR juxtapose LTCC along T-tubules at close distances $(\sim 12 \mathrm{~nm})$ (Forbes and Sperelakis, 1983). Individual dyads control the process of $\mathrm{Ca}^{2+}$ induced $\mathrm{Ca}^{2+}$ release, or CICR. The elementary event is a $\mathrm{Ca}^{2+}$ spark released from the SR by the opening of RyR in a single $\mathrm{Ca}^{2+}$ release unit (Cheng and Lederer, 2008). When an LTCC opens during an $\mathrm{AP}$, the local $\mathrm{Ca}^{2+}$ concentration in the dyad raises much more than cytosolic $\mathrm{Ca}^{2+}$, from a diastolic level of $100 \mathrm{nM}$ to more than $10 \mu \mathrm{M}$, sufficiently to activate RyR (Cannell and Kong, 2012). Not all RyR are localized at dyads; noncoupled RyR are activated through propagated $\mathrm{Ca}^{2+}$ release 
with a delay. Therefore, a large heterogeneity of the tubular system (e.g., due to T-tubule loss in HF) causes dyssynchrony of subcellular $\mathrm{Ca}^{2+}$ release during systole (Heinzel et al., 2011). During diastole, few spontaneous $\mathrm{Ca}^{2+}$ sparks occur due to the relatively low sensitivity of RyR to resting $\mathrm{Ca}^{2+}$ levels. A spontaneous release event is spatially confined, but when the $\mathrm{Ca}^{2+}$ sensitivity or the RyR increases through phosphorylation or oxidation, or when SR $\mathrm{Ca}^{2+}$ load is high, more spontaneous $\mathrm{Ca}^{2+}$ sparks summate in time and space into propagating $\mathrm{Ca}^{2+}$ waves.

The structural design of the dyad also provides an optimal setting for feedback mechanisms of $\mathrm{SR} \mathrm{Ca}^{2+}$ release on $\mathrm{Ca}^{2+}$ regulated membrane currents. Negative feedback through $\mathrm{Ca}^{2+}$ release-dependent inactivation of LTCC serves as a mechanism to limit $\mathrm{Ca}^{2+}$ influx during the initial phase of the AP (Sham, 1997). As release-dependent inactivation is immediate, following the fast rise and decline of local $\mathrm{Ca}^{2+}$ near dyads, some of the LTCC may recover from inactivation within a single beat during the AP plateau (Acsai et al., 2011). The local feedback of $\mathrm{Ca}^{2+}$ on LTCC may contribute to the intrinsic BVR of the AP in normal physiology (Antoons et al., 2015). Interestingly, the same study did not find a major role for the NCX in BVR, although immunohistochemistry and functional studies have suggested colocalization of a fraction of NCX with LTCC (10-15\% of total NCX) sensing local $\mathrm{Ca}^{2+}$ release in the dyadic subspace (Acsai et al., 2011; Scriven and Moore, 2013). In support of this notion, modulation of (dyadic) $\mathrm{Ca}^{2+}$ sparks by both reverse mode and forward mode NCX has been demonstrated (Neco et al., 2010; Biesmans et al., 2011).

To regulate CICR, the dyad harbors a repertoire of kinases and phosphatases that form macromolecular complexes with LTCC and RyR and regulate their levels of phosphorylation. PKA and CaMKII are key to the regulation of LTCC and RyR in the $\beta$-adrenergic and stretch response. PKA is targeted to LTCC and RyR via AKAPs, and transmits signals from $\beta$-ARs via cAMP (Catterall, 2015; Landstrom et al., 2017). Dyadic cAMP signals in the vicinity of LTCC and RyR are controlled by localized PDE activity (Kokkonen and Kass, 2017). It should be noted that exact mechanisms behind PKA regulation of RyR and its specific role in the $\beta$-adrenergic response are incompletely understood. Marx et al. (2000) proposed that PKA phosphorylation dissociates FKBP12.6 from RyR thereby enhancing RyR open probability. However, this mechanism remains questionable (Xiao et al., 2004). CaMKII is dually activated by $\mathrm{Ca}^{2+}$ and ROS (Maier and Bers, 2007), and possibly also by $\mathrm{NO}$ at high $\mathrm{Ca}^{2+}$ levels during $\beta$-adrenergic stimulation (Curran et al., 2014). Although CaMKII is targeted to both coupled and non-coupled RyR via unknown mechanisms, its activation is confined to the dyad, where it enhances the open probability of RyR and LTCC (Wehrens et al., 2004; Bers and Morotti, 2014).

\section{Reactive Oxygen Species}

In addition to phosphorylation mechanisms, ROS and NO have emerged as critical regulators of CICR. They modify LTCC and RyR function through redox modification of free cysteine residues. The action of ROS and NO is often multiphasic and bidirectional, depending on source, oxidant species, amount and timing and importantly, the local redox environment (Zima and Blatter, 2006). Typically, free radicals are short-lived and can only act on effectors in the close vicinity. Thus, redox modulation of $\mathrm{Ca}^{2+}$ in a cardiac myocyte is basically a tale of microdomain signaling of which the specific effects are determined by the subcellular location of the ROS/NO source and co-localization with its target proteins. Endogenous ROS are generated in the mitochondria as a by-product of respiration, and locally in the cytosol by specialized enzymes, such as NADPH oxidases (Burgoyne et al., 2012). Much of the $\mathrm{O}_{2}{ }^{-}$produced is rapidly converted to $\mathrm{H}_{2} \mathrm{O}_{2}$, a more stable and membrane permeable derivative. Endogenous NO is produced in relatively low concentrations by endothelial and neuronal isoforms of NOS (eNOS and nNOS, respectively) (Massion et al., 2003).

An important player in the redox control of dyadic $\mathrm{Ca}^{2+}$ is NOX2, a membrane-bound NADPH oxidase that resides in T-tubules. NOX2 is induced by fast pacing and stretch, and activates RyR via S-glutathionylation (Sánchez et al., 2005). RyR activation by rapid pacing also requires CaMKII, which itself is redox regulated (Erickson et al., 2008). Interestingly, the NOX2CaMKII regulation of RyR is restricted to the dyadic cleft. In pig myocytes that resemble human and have a significant population of non-coupled RyR, faster pacing significantly increased $\mathrm{Ca}^{2+}$ spark activity of dyadic RyR, but not the activity of non-coupled RyR. Additionally, NOX2 and CaMKII inhibition abolished $\mathrm{Ca}^{2+}$ sparks in dyadic regions, but not near non-coupled regions (Dries et al., 2013). At this point it cannot be concluded if NOX2derived ROS is upstream of CaMKII oxidation [as suggested in models of oxidative stress induced by angiotensin (Erickson et al., 2008; Purohit et al., 2013)] or whether NOX2 and CaMKII act in parallel. Furthermore, exact mechanisms of microdomainspecific activation of NOX2 and CaMKII in response to rapid pacing remain elusive. NOX2 is also activated by stretch. Prosser et al. (2011) have demonstrated that stretching a myocyte triggered an immediate burst of ROS and $\mathrm{Ca}^{2+}$ sparks. The ROS was derived from NOX2 as the response was sensitive to NOX2 inhibitors and absent in NOX2 deficient mice (Prosser et al., 2011).

In contrast to NOX2, mitochondria constitutively produce ROS. Mitochondria are located at a very short distance of dyadic regions [between 37 and $270 \mathrm{~nm}$ based on electron microscopy analysis of rat myocardium (Sharma et al., 2000)]. Several studies have shown that mitochondrial ROS can activate RyR (reviewed in Zhang H. et al., 2013), suggesting that basal ROS production by mitochondria is responsible for a significant portion of spontaneous $\mathrm{Ca}^{2+}$ sparks (Yan et al., 2008).

The LTCC also acts as a redox sensor due to free thiol groups in its $\alpha 1$-subunit (Muralidharan et al., 2016). Reported ROS effects on $\mathrm{Ca}^{2+}$ channel function are both stimulatory (Song et al., 2010), or inhibitory (Gill et al., 1995). This discrepancy might be due to differences in the phosphorylation state of the $\mathrm{Ca}^{2+}$ channel. Several serine/threonine kinases that regulate the channel are subjected to ROS modification, including PKA, PKC, and CaMKII (see Burgoyne et al., 2012, for review). The positive effects of phosphorylation might partially counterbalance the inhibitory effects of direct ROS oxidation of LTCC. During high oxidative stress, LTCC facilitation by CaMKII 
is likely the predominant effect, since the calcium antagonist nifedipine could suppress the induction of EADs by $\mathrm{H}_{2} \mathrm{O}_{2}$ (Xie et al., 2009). ROS regulates many other proteins of the $\mathrm{Ca}^{2+}$ machinery outside the dyad. The overall effect of sustained ROS is $\mathrm{Na}^{+}$and $\mathrm{Ca}^{2+}$ overload promoting even more ROS production via positive feedback and predisposing the cell to afterdepolarizations (Wagner et al., 2013).

Nitric oxide is both a positive and a negative regulator of excitation-contraction (EC) coupling underscoring the complexity of cardiac NO signaling (Simon et al., 2014; Farah et al., 2018). NO exerts its action via two pathways: an indirect pathway by the activation of sGC producing cGMP, and a direct pathway by $S$-nitrosylation of proteins. High levels of NO would predominantly stimulate the cGMP pathway causing negative inotropy, while low levels activate nitrosylation processes leading to positive inotropy (González et al., 2008). The mechanisms of nitrosylation, and particularly its effects on EC coupling, remain poorly understood. Despite much controversy, some consensus has emerged on the specific roles of eNOS and nNOS highlighting the importance of their subcellular localization in modulating $\mathrm{Ca}^{2+}$ handling proteins. Colocalization of eNOS and LTCC in caveolae at the sarcolemma favors $S$-nitrosylation and inhibition of LTCC (Wang et al., 2008). nNOS is targeted to the SR where it colocalizes with $\mathrm{RyR}$ and is therefore considered the prime NO modulator of dyadic $\mathrm{Ca}^{2+}$ (Barouch et al., 2002). NO nitrosylates RyR and increases its activity (Wang et al., 2010, but see also Zahradníková et al., 1997). The notion that the positive effects of nNOS are linked to its specific localization on the SR has been supported by a recent study that developed a transgenic mouse model in which nNOS was targeted to the sarcolemma and no longer co-localized with RyR (Carnicer et al., 2017). Interestingly, relocalization of nNOS, as may occur in $\mathrm{HF}$, produced the same negative effects on $\mathrm{I}_{\mathrm{CaL}}$ and contraction as eNOS. In normal physiology, NOS activity is controlled by $\beta$-adrenergic stimulation and stretch, as will be discussed in the next paragraphs.

\section{$\beta$-ADRENERGIC SIGNALING AND AFTERDEPOLARIZATIONS}

In the heart, enhanced sympathetic activity is a potent stimulus for generation of arrhythmias. The relationship between sympathetic stimulation and triggered activity has long been recognized, in vivo (Priori et al., 1988, 1990) and in vitro (Lazzara and Marchi, 1989). During $\beta$-adrenergic stimulation, DADs and EADs often coexist. When $\mathrm{Ca}^{2+}$ overload plays a role in afterdepolarization formation, as could be the case under $\beta$-adrenergic stimulation, both EADs and DADs can be abolished by ryanodine, suggesting a common dependence of these on $\mathrm{SR} \mathrm{Ca}^{2+}$ release under these conditions. In cardiac myocytes, $\beta$-ARs and their effector pathways targeting $\mathrm{Ca}^{2+}$ handling proteins are highly compartmentalized. In this paragraph, we will discuss the parallel activation of multiple molecular pathways by $\beta$-adrenergic subtypes, their specific end targets to controlling local and global $\mathrm{Ca}^{2+}$ release, and their impact on the generation of DADs and EADs.

\section{$\beta$-Adrenergic Signaling Pathway}

$\beta$-Adrenergic stimulation activates two pathways that operate in parallel: a PKA-dependent pathway that impacts on systolic $\mathrm{Ca}^{2+}$ through modulation of SR $\mathrm{Ca}^{2+}$ load, and a CaMKII pathway that regulates diastolic SR $\mathrm{Ca}^{2+}$ release (Figure 2A). Molecularly, the PKA signaling cascade is clearly defined. Upon activation, $\beta$-adrenergic agonists stimulate adenylate cyclase via Gs-coupled proteins raising cAMP levels that activates PKA (Bers, 2002). Subsequent phosphorylation of PKA substrates, including LTCC (causing increased $\mathrm{Ca}^{2+}$ influx) and PLB (accelerating SR $\mathrm{Ca}^{2+}$ uptake), results in enhancement of SR $\mathrm{Ca}^{2+}$ load. In cardiac myocytes, the compartmentation of cAMP signaling has been attributed to different $\beta$-AR subtypes that have distinct subcellular locations. $\beta 2$ receptors are preferentially located at T-tubules where they co-localize with LTCC in caveolae, while $\beta 1$ receptors are distributed more globally across T-tubules and surface sarcolemma. Using FRET sensors for cAMP, it was demonstrated that selective $\beta 1$ stimulation generates cAMP signals that propagate throughout the cell, whereas the $\beta 2$ AR signal is locally confined in T-tubules and specifically regulates LTCC during CICR (Nikolaev et al., 2006).

In vitro, PKA can also phosphorylate RyR (Marx et al., 2000), but in intact myocytes a functional role for PKA regulation of RyR remains controversial. Most evidence is in favor of CaMKII as the prime modulator of RyR during $\beta$-adrenergic stimulation. In response to adrenergic activation, CaMKII phosphorylates RyR and increases open probability when measured as SR $\mathrm{Ca}^{2+}$ leak (Curran et al., 2007) or diastolic $\mathrm{Ca}^{2+}$ sparks (Gutierrez et al., 2013). A recent study in pig myocytes suggested that CaMKII-dependent modulation of RyR during $\beta$-adrenergic stimulation was restricted to RyRs specifically in the dyadic cleft, and involved local activation of nNOS (Dries et al., 2016). The nNOS/CaMKII effects were not observed in RyR release sites that were not coupled to T-tubules. While there is conclusive evidence to support nNOS involvement in $\beta$-adrenergic modulation of RyR (Massion et al., 2003), the steps upstream from nNOS activation are less well defined. Some, but not all, studies suggested the involvement of Epac, a cAMP target parallel to PKA, leading to CaMKII autophosphorylation and downstream RyR phosphorylation (Pereira et al., 2007; Oestreich et al., 2009). A second pathway, independent of cAMP, involves PI3K and Akt as upstream activators of nNOS inducing CaMKII activation via nitrosylation (Curran et al., 2014). A recent study suggested that the Epac and nNOS pathway are interdependent and function largely in series (Pereira et al., 2017).

During $\beta$-adrenergic stimulation, the cAMP-PKA and nNOSCaMKII pathways operate in parallel. From the current evidence it is clear that PKA signaling is distributed more globally with robust effects on LTCC and SERCA, whereas CaMKII is highly localized and exerts stronger effects than PKA on RyR. $\mathrm{Ca}^{2+}$ current facilitation by CaMKII under $\beta$-AR has also been demonstrated (Dries et al., 2016). The integrated response is 
A

\section{$\beta$-Adrenergic Signaling}

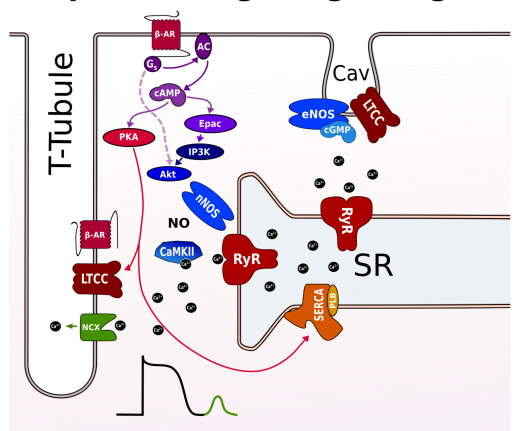

B

\section{Mechanotransduction}

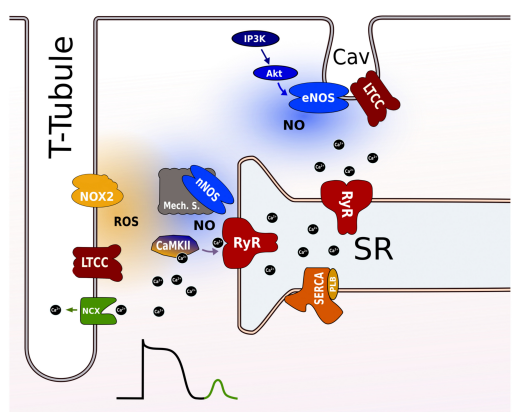

FIGURE 2 | Proposed pathways for inducing SR Ca ${ }^{2+}$ leak during $\beta$-adrenergic signaling and stretch in a ventricular cardiomyocyte. (A) $\beta$-AR raises cAMP levels via $\mathrm{G}_{\mathrm{s}}$-protein-dependent activation of AC that activates both PKA and Epac. PKA phosphorylates LTCC and PLB leading to more Ca ${ }^{2+}$ influx and faster uptake by SERCA into the SR. Epac activates nNOS and CaMKII via an PI3K and AkT signaling cascade promoting SR Ca ${ }^{2+}$ leak via RyR phosphorylation. The broken line indicates a cAMP and Epac-independent pathway for local activation of nNOS targeted to RyR in the dyad. RyR not coupled to LTCC in T-tubules are not modulated by CaMKII and nNOS. eNOS is localized to caveolae and exerts negative effects on LTCC during $\beta$-adrenergic stimulation. (B) Mechanotransduction involves ROS and NO for RyR activation. The ROS and NO pathway are independent and operate on different timescales via different mechanosensors. NOX2 produces ROS near RyR in the dyad increasing RyR activity possibly via oxidation of CaMKII. With a delay, nNOS is activated via an unknown mechanosensing mechanism. The enhanced SR $\mathrm{Ca}^{2+}$ leak promotes $\mathrm{Ca}^{2+}$ waves that activate a transient inward NCX current causing DAD. Caveolar eNOS is activated by stretch via PI3K-Akt and positively modulates EC coupling outside the dyad by mechanisms that are incompletely understood. See text for further details. AC, adenyl cyclase; $\beta$-AR, $\beta$-adrenergic receptor; cAMP, cyclic adenosine 3',5'-monophosphate; CaMKII, Ca ${ }^{2+}$ /calmodulin-dependent protein kinase II; EC, excitation contraction; DAD, delayed afterdepolarizations; eNOS, endothelial nitric oxide synthase; Epac, exchange protein activated by cAMP; LTCC, L-type Ca channel; NCX, Na+/Ca ${ }^{2+}$ exchanger; NO, nitric oxide; NOX2, NADPH oxidase type 2; nNOS, neuronal nitric oxide synthase; PI3K, phosphoinositide 3-kinase; PKA, protein kinase A; PLB, phospholamban; ROS, reactive oxygen species; RyR, ryanodine receptor; SERCA, SR Ca ${ }^{2+}$-ATPase; SR, sarcoplasmic reticulum.

enhancement of LTCC currents, SR Ca ${ }^{2+}$ load and leak. Together, these effects are able to favor both EADs and DADs.

\section{$\mathrm{Ca}^{2+}$-Dependent Mechanisms of Afterdepolarizations During $\beta$-Adrenergic Stimulation}

The link between $\beta$-adrenergic stimulation, RyR-mediated $\mathrm{Ca}^{2+}$ leak and arrhythmogenesis has been most convincingly demonstrated in the clinical case of catecholaminergic polymorphic ventricular tachycardia (CPVT). Patients with CPVT carry mutations in RyR that increase the open probability of the receptor, or in calsequestrin (Casq2) where SR $\mathrm{Ca}^{2+}$ buffering is hindered and/or the interaction of Casq 2 and RyR is altered (Cerrone et al., 2009). Introducing a CPVT associated RyR mutation in a mouse model, for example, resulted in a higher rate of $\mathrm{Ca}^{2+}$ sparks, waves and DADs in myocytes, and development of bidirectional ventricular tachycardia after exposure to catecholamines (Cerrone et al., 2005; Liu et al., 2006; Fernández-Velasco et al., 2009). The higher incidence of DADs and triggered activity has been attributed to increased RyR sensitization to $\mathrm{Ca}^{2+}$ (lowering the SR threshold for $\mathrm{Ca}^{2+}$ waves), and the enhanced SR $\mathrm{Ca}^{2+}$ by catecholamines (Fernández-Velasco et al., 2009; Kashimura et al., 2010). DAD occurrence also critically depends on the balance between SR $\mathrm{Ca}^{2+}$ load and the diastolic interval. Short durations reduce the time for SR refilling and recovery, and hence the likelihood of DADs. CPVT patients sometimes develop bradycardia. In this population the slow supraventricular rate has been suggested as the primary cause of ventricular arrhythmias (Faggioni et al., 2013), which may explain the reduced response of some patients to $\beta$-blockers (Priori et al., 2002). During bradycardia, particularly the Purkinje cells of the conduction system are prone to developing DADs and present a major source of focal activity in CPVT (Cerrone et al., 2007).

In conditions of excessive $\mathrm{Ca}^{2+}$ load, DADs and EADs often appear simultaneously (Priori and Corr, 1990; Volders et al., 1997; Antoons et al., 2007). A study by Johnson et al. (2013) in dog ventricular myocytes proposed a mechanism that coupled diastolic DADs to increased BVR and EADs. In the presence of isoproterenol, diastolic $\mathrm{Ca}^{2+}$ waves and DADs frequently appeared between beats. After a DAD, the duration of the next AP was consistently prolonged, related to an increase in $\mathrm{I}_{\mathrm{CaL}}$. The Ca transient during CICR was smaller after a DAD (presumably due to partial SR depletion), and modeling and voltage-clamp analysis explained the $\mathrm{I}_{\mathrm{CaL}}$ facilitation by a reduction of $\mathrm{Ca}^{2+}$ dependent inactivation of $\mathrm{I}_{\mathrm{CaL}}$. The feedback of DAD on $\mathrm{I}_{\mathrm{CaL}}$ caused significant BVR. Furthermore, because of the prolonged $\mathrm{AP}$ after a DAD, new $\mathrm{Ca}^{2+}$ waves could be generated before the end of repolarization and form EADs.

The phenomenal observation of $\mathrm{Ca}^{2+}$ sparks and waves that occur due to spontaneous (not triggered) openings of RyR clusters during diastole is well known (Cheng and Lederer, 2008). Triggered $\mathrm{Ca}^{2+}$ sparks, i.e., produced by LTCC openings during CICR, occur near-synchronously at the start of the $\mathrm{Ca}^{2+}$ transient and are not expected to occur during relaxation because of refractoriness of the RyR and SR $\mathrm{Ca}^{2+}$ content. However, using high sensitivity detectors during confocal imaging in rabbit ventricular myocytes, Fowler et al. (2018) detected $\mathrm{Ca}^{2+}$ sparks during the decay of the $\mathrm{Ca}^{2+}$ transient. They explained the 
occurrence of these late $\mathrm{Ca}^{2+}$ sparks by the ability of release sites to recover from refractoriness during the plateau phase of the AP to become reactivated either by cytosolic $\mathrm{Ca}^{2+}$ itself, or by stochastic openings of LTCC. Late $\mathrm{Ca}^{2+}$ sparks are more readily observed when CaMKII activity is increased, as was reported in a mouse model of CaMKII $\delta$ c overexpression (Guo et al., 2012). CaMKII phosphorylation of LTCC causes a shift in the distribution of LTCC into high-activity gating modes and accelerates recovery from inactivation (Sham et al., 1995; Guo and Duff, 2006), which could explain the facilitation of late $\mathrm{Ca}^{2+}$ sparks by CaMKII. Interestingly, repetitively firing of late $\mathrm{Ca}^{2+}$ sparks produced microscopic waves of $\mathrm{Ca}^{2+}$ release presenting a new paradigm of electrical instability underlying BVR and EAD (induced by a DAD-like mechanism during the AP plateau), particularly in settings of HF with prolonged AP and increased CaMKII activity.

A final mechanism of EAD seen with $\beta$-AR relates to the dynamic modulation of $\mathrm{Ca}^{2+}$ window currents through $\mathrm{Ca}^{2+}$-dependent feedback. The mechanism is independent of spontaneous $\mathrm{Ca}^{2+}$ events (unlike the mechanisms discussed above) but reflects local feedback of $\mathrm{SR} \mathrm{Ca}^{2+}$ release on LTCC during CICR. In the classical view, EAD are caused by voltage-dependent recovery of inactivated LTCC. Inactivation and recovery of LTCC also have a $\mathrm{Ca}^{2+}$-dependent component (Sipido et al., 1995; Sham, 1997), dynamically shaping $\mathrm{Ca}^{2+}$ window currents during a single beat. In dog and pig myocytes, we observed that under isoproterenol $\mathrm{Ca}^{2+}$-dependent recovery of window currents was faster than the decay of global $\mathrm{Ca}^{2+}$ transients, relatively unaffected by slow $\mathrm{Ca}^{2+}$ buffers and absent when SR Ca ${ }^{2+}$ release was inhibited (Antoons et al., 2007; Acsai et al., 2011). These data strongly suggest that release-dependent recovery of window currents is driven by local changes in dyadic $\mathrm{Ca}^{2+}$. The $\mathrm{Ca}^{2+}$-dependent regulation of $\mathrm{Ca}^{2+}$ window currents seem to require sufficiently high levels of dyadic $\mathrm{Ca}^{2+}$, or local activation of CaMKII, as the dynamic inactivation and recovery process was no longer observed in the absence of isoproterenol. Enhanced dynamic modulation of window LTCC by dyadic $\mathrm{Ca}^{2+}$ release is a suggested source of BVR (Antoons et al., 2015), and may contribute to an increased incidence of EADs under $\beta$-AR stimulation (Antoons et al., 2007).

\section{MECHANICAL LOAD AND AFTERDEPOLARIZATIONS}

Acute stretching of the heart destabilizes membrane potential and causes DADs and EADs (Franz et al., 1989). This arrhythmogenic activity is caused by negative feedback mechanisms that integrate mechanical and electrical activity of cardiac myocytes and presumably involve $\mathrm{Ca}^{2+}$ (Ravens, 2003). The myocardium responds to stretch by a more powerful contraction, a phenomenon referred to by Frank Starling (Sagawa et al., 1990). The intrinsic adaptation to changes in mechanical load has a second slower component of enhanced contractility described by the Anrep effect (von Anrep, 1912). Early work in intact cardiac muscle had not observed significant changes in diastolic and systolic global $\mathrm{Ca}^{2+}$ levels during the initial stretch response
(Allen and Kurihara, 1982), which has argued against a major role for $\mathrm{Ca}^{2+}$ in stretch-induced arrhythmias. More recently, this view has been challenged by experiments that confocally monitored $\mathrm{Ca}^{2+}$ sparks and waves during stretch, suggesting that local $\mathrm{Ca}^{2+}$ release could account for at least part of the Frank Starling response (Petroff et al., 2001). Since then, a complex picture of mechanosensitive $\mathrm{Ca}^{2+}$ signaling has emerged that operates over a wide range of time scales. Within milliseconds, a small diastolic stretch triggers a burst of $\mathrm{Ca}^{2+}$ sparks (Iribe et al., 2009). When sustained, $\mathrm{Ca}^{2+}$ accumulates over minutes via stretch-induced autocrine/paracrine signaling participating in the Anrep effect (Cingolani et al., 2013). When stress becomes chronic, elevated $\mathrm{Ca}^{2+}$ influx activates gene expression leading to hypertrophy (Tavi et al., 2001; Gómez et al., 2013).

\section{RyR Mechanosensitivity}

Stretch-dependent regulation of the $\mathrm{Ca}^{2+}$ system is operated via the process of mechanotransduction. Its mechanisms involve many signaling cascades targeting a diversity of intracellular $\mathrm{Ca}^{2+}$ sources, including the SR and mitochondria (Schönleitner et al., 2017). Furthermore, mechanotransduction operates via different classes of mechanosensors of which the activation seems to depend on the mechanical environment of the myocyte, which in experimental settings is defined by the dimensionality of the stretch system (Chen-Izu and Izu, 2017). The modulation of RyR by mechanical force has been a focus of investigation after the first demonstration in a 3D cell-in-gel system that stretch can trigger $\mathrm{Ca}^{2+}$ sparks (Petroff et al., 2001). Subsequently, ROS and NO have been identified as key molecules in RyR mechanosensitivity (Figure 2B). NOX2 activation has been proposed as the principle mechanosensor underlying the initial fast response of $\mathrm{Ca}^{2+}$ sparks to stretch (Prosser et al., 2011). Stretch-induced ROS by NOX2 is fast, transient and confined near the dyad to permit rapid and reversible modification of RyR. It is therefore believed that the NOX2 pathway enhances CICR efficiency without changes in systolic $\mathrm{Ca}^{2+}$ and serves as an adaptation to beatto-beat variations in preload contributing to the Frank Starling response.

Cardiac stretch also stimulates cardiomyocytes to produce NO (Khairallah et al., 2012). Mechanical stimulation of NO elevates the systolic $\mathrm{Ca}^{2+}$ transient and produces spontaneous $\mathrm{Ca}^{2+}$ sparks during diastole, as was demonstrated in myocytes contracting in-gel against a higher preload or afterload (Petroff et al., 2001; Jian et al., 2014). In these settings, NO was produced through activation of constitutive NOS by phosphorylation via the PI3K-Akt pathway (Petroff et al., 2001). Pharmacological inhibition or genetic deletion to differentiate between eNOS and nNOS pathways revealed that both isoforms were involved in the downstream effects on systolic $\mathrm{Ca}^{2+}$, but only nNOS had a role in the induction of $\mathrm{Ca}^{2+}$ sparks (Jian et al., 2014). The divergent effects of eNOS and nNOS have been explained by their subcellular location. nNOS is localized at the dyad in close proximity of RyR, while eNOS is spatially confined in caveolae more distant from RyR release sites (Xu et al., 1999). Downstream from nNOS signaling, CaMKII was also found to modulate afterload-induced $\mathrm{Ca}^{2+}$ sparks. The mechanically 
induced SR $\mathrm{Ca}^{2+}$ leak by nNOS is expected to deplete the SR of $\mathrm{Ca}^{2+}$, however, $\mathrm{SR} \mathrm{Ca}{ }^{2+}$ content is maintained presumably via enhanced SERCA Ca ${ }^{2+}$ reuptake by nNOS (Vielma et al., 2016).

The NO-mediated increase of the $\mathrm{Ca}^{2+}$ transient to compensate for greater mechanical load typically appears with a delay of seconds and minutes, possibly participating in the Anrep effect. Trans-sarcolemmal $\mathrm{Ca}^{2+}$ influx also contributes to the slow $\mathrm{Ca}^{2+}$ loading during stretch. One of the proposed mechanisms is increased activity of $\mathrm{Na}^{+} / \mathrm{H}^{+}$exchanger through mitochondrial ROS release downstream of stretch-induced angiotensin signaling (Cingolani et al., 2013). The result is an increase in intracellular $\mathrm{Na}^{+}$that stimulates reverse NCX loading the cell with $\mathrm{Ca}^{2+}$. $\mathrm{Na}^{+}$and $\mathrm{Ca}^{2+}$ influx through non-selective cationic SAC may further contribute (Calaghan et al., 2004). Thus, slow adaptation to stretch is viewed as an enduring signal achieved by concerted action of local nNOS activity to fine-tune local $\mathrm{Ca}^{2+}$ release and transsarcolemmal $\mathrm{Ca}^{2+}$ and $\mathrm{Na}^{+}$influx to gain more $\mathrm{Ca}^{2+}$.

\section{$\mathrm{Ca}^{2+}$-Dependent Mechanisms of Stretch-Induced Arrhythmias}

While mechano-sensitization of RyR is part of an effective adaptation to preload and afterload by increasing the efficiency of local $\mathrm{Ca}^{2+}$ release, it also produces spontaneous $\mathrm{Ca}^{2+}$ sparks during diastole. In the normal heart, stretch-induced $\mathrm{Ca}^{2+}$ sparks are locally confined. Under certain conditions, when more $\mathrm{Ca}^{2+}$ sparks arise synchronously to form $\mathrm{Ca}^{2+}$ waves, the load-adaptive $\mathrm{Ca}^{2+}$ system could turn into an arrhythmogenic mechanism. The stretch-induced increase in ROS, $\mathrm{Ca}^{2+}$ sparks and velocity of propagating $\mathrm{Ca}^{2+}$ waves is graded, i.e., increases with increasing amount of stretch (Miura et al., 2015). Thus, large stretches, such as in dilated hearts, are more likely to trigger ventricular ectopy (Hansen et al., 1990). Mechanical dyssynchrony, often due to structural tissue heterogeneity, is a further compromising factor. In case of dyssynchronous contractions, $\mathrm{Ca}^{2+}$ waves arise from a non-SR source as result from $\mathrm{Ca}^{2+}$-dissociation from the contractile filaments during late relaxation of the non-uniform cardiac muscle (Miura et al., 2008).

More ROS can also by produced by hypersensitivity of mechanosensitive signaling due to upregulation of a molecular component, as was demonstrated for a mouse model of Duchenne muscular dystrophy that showed upregulation of NOX2 and produced $\mathrm{Ca}^{2+}$ waves in response to moderate stretch (Prosser et al., 2011). In addition to DADs, ROS also activates EADs, via reactivation of $\mathrm{I}_{\mathrm{CaL}}$ (Song et al., 2010), or enhanced late $\mathrm{Na}^{+}$current (Song Y. et al., 2006). While RyR, INaL, and LTCC can be directly activated by oxidation (Xu et al., 1998; Morita et al., 2003; Kassmann et al., 2008), redox modification of CaMKII seems to be crucially involved in ROS modulation of arrhythmogenic INaL and LTCC currents (Morita et al., 2009; Wagner et al., 2011). Of note, most electrophysiology studies applied $\mathrm{H}_{2} \mathrm{O}_{2}$ as an exogenous source of ROS. There are no current data to confirm if endogenous ROS produced by NOX2 during stretch behaves similarly. Source matters, as mitochondrial ROS caused a reduction of INa (Liu et al., 2010).
While ROS is a ubiquitous proarrhythmic signal, NO generate opposite pro- and antiarrhythmic signals that can be partly explained by divergent effects of eNOS and nNOS on $\mathrm{Ca}^{2+}$ handling proteins. Mice with targeted disruption of eNOS had a higher incidence of arrhythmias induced by ouabain (Rakhit et al., 2001) or $\beta$-adrenergic stimulation (Wang et al., 2008), confirming earlier work reporting on the protective effects of NO against ventricular arrhythmias in dogs (Vegh et al., 1992). The antiarrhythmic effects have been attributed to $\beta$-adrenergic antagonism of eNOS via reduction of $\mathrm{I}_{\mathrm{CaL}}$ in a cGMP-dependent manner. Likewise, nNOS knockout mice suffered more from arrhythmias after myocardial infarction than their WT littermates. Because an $\mathrm{I}_{\mathrm{CaL}}$ blocker reduced VF incidence, the authors concluded that nNOS is antiarrhythmic through $\mathrm{I}_{\mathrm{CaL}}$ inhibition via direct nitrosylation (Burger et al., 2009). Nitrosylation of the $\mathrm{Na}^{+}$channel is also coupled to nNOS activity (Ahern et al., 2000). Conversely, when nNOS is activated by stretch or catecholamines in cardiac myocytes, local NO-CaMKII signals produce arrhythmogenic $\mathrm{Ca}^{2+}$ waves that originate from dyadic RyR (Curran et al., 2014; Jian et al., 2014). Giving the pro-arrhythmic actions of isoproterenol in vivo, it is reasonable to argue that during $\beta$-adrenergic stimulation in the presence of mechanical load, pro-arrhythmogenic nNOS signaling prevails.

In unloaded myocytes, the $\mathrm{I}_{\mathrm{TI}}$ following a $\mathrm{Ca}^{2+}$ wave is mainly produced by NCX. In stretched myocytes, a significant contribution of stretch-activated channels is anticipated. Stretchactivated non-selective cation currents (SACNS) have been functionally demonstrated in ventricular myocytes at the wholecell and single-level (Craelius et al., 1988). While it is unlikely that $\mathrm{Na}^{+}$and $\mathrm{Ca}^{2+}$ conducting SACNS participate in stretchinduced $\mathrm{SR} \mathrm{Ca}^{2+}$ release in ventricular myocytes (Iribe et al., 2009), they may contribute to destabilize the resting membrane potential by generating inward current during diastole. Studies in whole hearts demonstrating anti-arrhythmic effects of GsMTx4, a specific SACNS blocker, support the involvement of SAC in stretch-induced arrhythmias (Wang et al., 2016). The search for a 'true' SACNS, a structural homolog to the bacterial SAC that can be directly gated by membrane tension (Sukharev et al., 1994), is still ongoing. Interestingly in this regard is the discovery of Piezo channels in a neuroblastoma cell line (Coste et al., 2010). The biophysiological profile of Piezo matches endogenous cardiac SACNS, including weak voltage dependency, single channel conductance, inactivation, and sensitivity to GsMTx-4 (Gottlieb, 2017), and is therefore a promising candidate. Piezo is expressed at low levels in the heart (Coste et al., 2010), but its role in cardiac function has yet to be established.

In the heart, the search for cardiac SACNS has been largely focused on the transient receptor potential canonical (TRPC) channel family. The activation of TRP channels is polymodal, and some members are directly activated by membrane deformation (Inoue et al., 2009), although this remains somewhat controversial (Gottlieb et al., 2008). Two subtypes, TRPC3 and TRPC6, have been proposed as potential candidates participating in the slow force response (Yamaguchi et al., 2017). Hyperactive TRPC3 (Doleschal et al., 2015) or TRPC6 (Seo et al., 2014) amplified the slow inotropic response to stretch resulting in $\mathrm{Ca}^{2+}$ 
overload and arrhythmogenesis. Doleschal et al. (2015) explained the pro-arrhythmia of TRPC3 by a $\mathrm{Ca}^{2+}$ overload dependent mechanism that involves spatial uncoupling between TRPC3 and NCX1 in specialized microdomains disrupting the tight regulation of NCX by local $\mathrm{Ca}^{2+}$ and $\mathrm{Na}^{+}$. This thinking is in line with the conceptual view that TRPC channels have access to localized $\mathrm{Ca}^{2+}$ signaling microdomains that are separated from contractile dyadic signaling (Houser and Molkentin, 2008). The microdomain concept was initially proposed to explain the role of TRPC channels in the activation of the NFAT/calcineurin axis linking pathophysiological hypertrophy to chronic mechanical stretch (Kuwahara et al., 2006; Makarewich et al., 2014). It has been well established that structural and functional remodeling in pathological cardiovascular stress predisposes the heart to arrhythmias (Nattel et al., 2007; Orini et al., 2017).

\section{Linking Mechanotransduction and Adrenergic Signaling}

Thus far, ROS, NO, and CaMKII have been identified as the prime mediators of RyR mechanosensitivity in the intrinsic adaptation of contractile force to load. In vivo, intrinsic force adaptation is modulated by sympathetic activation by imposing a higher load on the heart through modulation of vascular tone. The myocyte can respond to higher mechanical and adrenergic stress through activation of mechanotransduction and adrenergic signaling networks, as discussed above and depicted in Figure 2, but interactions have not been systematically investigated. The mechanotransduction pathway shows both the rapid preloadinduced NOX2 and slower afterload-induced NO branch, that most probably operate independently (Jian et al., 2014). It is also unlikely that NOX2 is directly involved in $\beta$-adrenergic signaling, since ROS scavengers failed to prevent increases in $\mathrm{Ca}^{2+}$ spark frequency in quiescent cells that were treated with isoproterenol (Gutierrez et al., 2013). It should be noted that NOX2 can possibly become activated during $\beta$-adrenergic signaling as an indirect consequence of chronotropic effects (Dries et al., 2013).

nNOS is centrally involved in both stretch- and adrenergically induced $\mathrm{Ca}^{2+}$ sparks, most likely via oxidation of downstream CaMKII (Gutierrez et al., 2013; Jian et al., 2014). It is therefore tempting to speculate that nNOS and CaMKII act as primary integrators of mechanotransduction and adrenergic RyR signaling networks. The assumption that co-activation of nNOS has a cumulative effect on RyR activity remains to be determined.

The eNOS effects are less clearly defined. eNOS is compartmentalized in caveolae at T-tubules and sarcolemma. In sarcolemmal caveolae, eNOS colocalizes with $\beta$-ARs and LTCC allowing NO to mitigate $\beta$-adrenergic inotropy through inhibition of LTCC by local cGMP (Wang et al., 2008). It is conceivable that a stretch activation of the eNOS-AktPI3K pathway positively modulates EC coupling gain in T-tubular caveolae, while negatively regulating the $\beta$-adrenergic response in a different subset of caveolae at the surface sarcolemma.

\section{HEART FAILURE AND AFTERDEPOLARIZATIONS}

Heart failure is associated with extensive cardiac remodeling, at both the structural and functional levels. Remodeling due to HF occurs for a number of reasons, however, it is in part, due to altered stress on the ventricular wall (Kehat and Molkentin, 2010).

Remodeling can lead to an increased propensity for complex ventricular arrhythmias and sudden cardiac death, and these are seen in over half of the patients presenting with $\mathrm{HF}$ with reduced ejection fraction. For these reasons it is imperative to understand the mechanisms that are responsible for the increased arrhythmia incidence in this population (Janse, 2004).

Purkinje fibers isolated from infarcted sections of human hearts have been shown to have significantly longer APD than those from non-infarcted zones, resulting in marked dispersion of APD in infarcted and adjacent zones. Furthermore, both epinephrine and the cardiac glycoside, ouabain, were able to induce DADs in these fibers (Dangman et al., 1982). Previous work using human trabeculae has also shown that there is an increased propensity for triggered activity in tissue from HF patients (Vermeulen et al., 1994). Further work from the Amsterdam group also showed that, in contrast to many animal species, norepinephrine induces APD prolongation in ventricular myocytes from human failing hearts, as well as EADs. These alterations were ascribed to an increase in both the calcium peak current and window current (Veldkamp et al., 2001).

In addition to the alterations in arrhythmia incidence in HF, it has been well described that the failing heart has a reduced responsiveness to elevated catecholamine levels, at least in endstage $\mathrm{HF}$, due to alterations in expression of $\beta$-ARs (Bristow et al., 1982; Ungerer et al., 1993). Interestingly, more recent work has also shown that in a patient cohort with HF, BVR of ventricular AP duration was increased during an autonomic challenge associated with increased sympathetic activity (Porter et al., 2017).

Taking these data together leads us to believe that modifications in signaling underlying $\beta$-adrenergic responsiveness and stretch may contribute to the increased occurrence of arrhythmias in these patient populations. Therefore, if we are able to understand the precise changes that occur in these systems during HF, we may get a better hold on the processed occurring, with an outlook of preventing and/or treating the, potentially, maladaptive remodeling (see below).

\section{Global Remodeling}

At the gross structural level, the geometry of the heart changes as a result of $\mathrm{HF}$, becoming less elliptical and more spherical (Cohn et al., 2000). HF is associated with a progressive enlargement of the left ventricle, with increases in end-systolic left ventricular wall stress being seen (Florea et al., 1999), which may have detrimental effects on mechanosensitive mechanisms involved 
in arrhythmia formation, and also contribute to the cellular arrhythmogenic remodeling.

\section{Ion Channel Remodeling}

At the level of the single myocyte, changes in HF include alterations in the densities of various membrane channels, which contributes to the increase in APD seen in the majority of HF models and in patients (Beuckelmann et al., 1993; Tomaselli and Marbán, 1999). One of the most consistent findings with regards to current alterations in $\mathrm{HF}$ is the decrease in the inwardly rectifying potassium current, $\mathrm{I}_{\mathrm{K} 1}$, which contributes to maintaining the resting membrane potential as well as contributing to terminal repolarization (Beuckelmann et al., 1993; Nerbonne and Kass, 2005). Furthermore, the $\beta$-adrenergic regulation of $I_{K 1}$ has also been shown to be significantly reduced in myocytes isolated from HF patients (Koumi et al., 1995). Reduced $\mathrm{I}_{\mathrm{K} 1}$, will mean that a smaller $\mathrm{I}_{\mathrm{TI}}$ will be required to cause the same amplitude of DAD, or even triggered AP, and therefore altered regulation of this current in HF has major implications in the potential arrhythmogenic outcomes. An interesting recent study, however, showed that sympathetically -induced arrhythmias could not be induced when $\mathrm{I}_{\mathrm{K} 1}$ was inhibited in isolation in Langendorff-perfused rabbit hearts indicating that synergistic activity between multiple pathways, including altered RyR sensitivity, was required for arrhythmia induction (Myles et al., 2015).

Another potassium current that is of great interest when it comes to $\beta$-adrenergic modulation, is the slow rectifier, $I_{\mathrm{Ks}}$. $\mathrm{I}_{\mathrm{Ks}}$ function is prominent during $\beta$-adrenergic stimulation when it promotes AP shortening, to counteract the increase in inward $\mathrm{Ca}^{2+}$ current, thus providing critical "reserve" when other repolarizing currents are impaired (Jost et al., 2005; Varró et al., 2000; Volders et al., 2003). Although Veldkamp et al. (1995) could not detect this current in myocytes isolated from patients with cardiomyopathy, a number of animal models have indicated that this current is downregulated in HF (Tsuji et al., 2000; Li et al., 2002). A decrease in this current during intense sympathetic stimulation will lead to an increase in APD, and an increased tendency for afterdepolarizations. Furthermore, research from our own group has shown the key role that $\mathrm{I}_{\mathrm{Ks}}$ plays in preventing excessive BVR during $\beta$-AR stimulation, which may also contribute to the arrhythmogenic substrate generated when this current is downregulated (Johnson et al., 2010, 2013).

The importance of both $I_{K 1}$ and $I_{K s}$ and their regulation by $\beta$-adrenergic stimulation in HF were recently highlighted by a study from the Bers' group. In this manuscript, the physiologically relevant AP-clamp technique was utilized to show that under $\beta$-adrenergic stimulation, reduced $\mathrm{I}_{\mathrm{Ks}}$ responsiveness limits the integrated repolarizing potassium currents in a rabbit model of HF. Furthermore, an increase in APD BVR was seen in HF myocytes. Taken together these data illustrate the importance that these currents may play in arrhythmia generation in HF, especially under sympathetic stimulation (Hegyi et al., 2018a).

Apart from the acute effects of adrenergic stimulation on channel activity, one must also consider the effect of sustained sympathetic activation. A recent study did just this by investigating the effects of sustained adrenergic stimulation on $\mathrm{I}_{\mathrm{Ks}}$ dynamics. In that particular study, they showed that $\mathrm{I}_{\mathrm{Ks}}$ was reduced after continued $\beta$-AR stimulation, and this was mediated by CaMKII, a signaling molecule involved in both $\beta$-AR and mechanosensitive stimulated arrhythmias (Shugg et al., 2018). If this effect contributes to the increased incidence of arrhythmias in HF is currently unknown and should be the subject of further work.

With regards to the acute effect of HF on SACNS, that may also contribute to stretch-induced arrhythmias, multiple laboratories have shown that TRPC channel expression and activity are upregulated in pathological hypertrophy and HF (Eder and Molkentin, 2011). Furthermore, to our knowledge, to date only one study has investigated the level of Piezo channels in HF, with that study providing evidence of an upregulation in HF. However, the functional consequences of this upregulation are currently unknown and should be the subject of further research (Liang et al., 2017).

\section{Excitation-Contraction Coupling Remodeling}

As previously stated, the synchronous rises in $\mathrm{Ca}^{2+}$ leading to efficient ECC is due, in part, to the tight opposition of RyRs and LTCCs in the T-tubules in healthy ventricular myocytes. There is an abundance of literature describing a loss of T-tubules during HF (Lyon et al., 2009; Guo et al., 2013; Dries et al., 2018a), In addition to the loss of the concerted effort for successful ECC that the loss of T-tubules will bring, deleterious $\mathrm{Ca}^{2+}$ handling leading to arrhythmia may also result. A recent study investigated the potential mechanisms behind T-tubule disruption in post-infarction failing rat hearts. In that study, they showed that elevated wall stress was associated with disruption of the T-tubular structure and this was associated with decreased levels of junctophilin 2, which is a critical dyadic anchor. Furthermore, they carried out studies on loaded papillary muscles, which confirmed a direct role of wall stress on regulation of T-tubule organization (Frisk et al., 2016). Taken together these data indicate the importance that stretch has in developing the HF phenotype when it comes to subcellular structure of the myocyte. Alterations in location of relevant signaling pathways that may also be induced by this loss of cellular architecture will be discussed later (see the Section "Local (Microdomain) Remodeling").

As the current generated via the NCX appears to be the major player responsible for the $\mathrm{I}_{\mathrm{TI}}$ that initiates DADs, and perhaps EADs, one also needs to consider how the function of this exchanger is altered in HF. Interestingly, a number of in vitro studies have suggested that stretch of adult myocytes increases NCX expression (Sipido et al., 2002). These data may lead us to believe that the increase stretch 'felt' by the in situ myocyte may also lead to an increase in NCX in HF. Indeed, the majority of studies have shown that NCX is increased in HF (Sipido et al., 2002; Schillinger et al., 2003), although we should approach these data with caution due to the fact that expression levels do not necessarily give an indication of activity, especially when considering an exchanger where ion concentrations, phosphorylation state [of partner proteins (e.g., phospholemman) as well as NCX itself] in addition to other 
factors will ultimately influence the current generated by the exchanger.

One of the major influences on NCX activity is the intracellular $\mathrm{Ca}^{2+}$ concentration. It is well known that cardiomyocytes isolated from failing hearts (with reduced ejection fraction) show altered $\mathrm{Na}^{+}$and $\mathrm{Ca}^{2+}$ haemostasis. The modified $\mathrm{Ca}^{2+}$ handling is characterized by decreased $\mathrm{Ca}^{2+}$ transients, enhanced diastolic $\mathrm{SR} \mathrm{Ca}^{2+}$ release and diminished $\mathrm{SR} \mathrm{Ca}^{2+}$ reuptake, which all contribute to altered $\mathrm{Ca}^{2+}$ concentrations 'seen' by the NCX (Hasenfuss and Pieske, 2002; Kho et al., 2012; Luo and Anderson, 2013) . Additionally, modeling studies have shown that that both dyadic and SR $\mathrm{Ca}^{2+}$ influence the appearance of DADs in addition to alterations in $\mathrm{Ca}^{2+}$ diffusion across the cell and $\mathrm{Ca}^{2+}$ uptake into the SR (Fink et al., 2011).

One of the first papers investigating $\mathrm{Ca}^{2+}$ sparks in myocytes from patients with $\mathrm{HF}$ indicated that alterations in the $\mathrm{Ca}^{2+}$ release mechanisms must be one of the mechanisms underlying EC coupling, in addition to alterations in SR $\mathrm{Ca}^{2+}$ load (Lindner et al., 2002). One of the driving forces behind this is the altered open probability of RyRs, which is governed by multiple factors, and has not been without controversy over the years (Dobrev and Wehrens, 2014). Interestingly, recent work has shown that stabilizing the RyR, using dantrolene, is able to prevent DADs in myocytes isolated from HF patients (Hartmann et al., 2017). Over the next few paragraphs, we will discuss how the major controllers of RyR stability, that also govern stretch and/or $\beta$-adrenergic signaling (namely CaMKII and ROS), can be affected in $\mathrm{HF}$.

CaMKII phosphorylation of RyR appears to play an important role in arrhythmogenesis and sudden cardiac death in mice with HF (van Oort et al., 2010). Analysis from ventricular tissue from patients with either dilated or ischemic cardiomyopathy have shown that there is an increase in the levels of CaMKII $\delta$, the major isoform of CaMKII in the heart (Sossalla et al., 2010). Interestingly, single myocytes isolated from mice overexpressing CaMKII $\delta$ are more liable to show DADs and spontaneous APs under $\beta$-adrenergic stimulation when compared to wild type mice (Sag et al., 2009). This increase in CaMKII seen in HF could directly promote arrhythmia formation by not only increasing diastolic $\mathrm{Ca}^{2+}$ leak via RyR phosphorylation, but also by promoting increases in the late $\mathrm{Na}^{+}$current (Wagner et al., 2006), a current that has already been shown to be increased in $\mathrm{HF}$, and incriminated in increased BVR and arrhythmia formation under these conditions (Maltsev et al., 2007).

The activity of CaMKII itself is under control of many different regulators, including ROS (as stated above and shown in Figure 2), which is detrimentally altered in HF. ROS also as having their own independent effects on RyR and other components of the $\mathrm{Ca}^{2+}$ handling machinery (dependent on the source of the ROS). In HF, just as in normal physiology, ROS has a number of different sources including NOX2, mitochondria and uncoupled NOS (Sag et al., 2013).

Interestingly, NOX2 expression and/or activity has also been shown to be increased in end-stage human $\mathrm{HF}$ in a number of studies, supporting the potential involvement of this pathway in the formation of ROS that may interfere with $\mathrm{Ca}^{2+}$ handling and lead to subsequent arrhythmias (Zhang M. et al., 2013). Furthermore, the elevated intracellular $\mathrm{Na}^{+}$concentration seen in HF promotes the production of mitochondrial ROS (Kohlhaas et al., 2010; Viatchenko-Karpinski et al., 2014), which could ultimately lead to the potential for a vicious circle of proarrhythmic signaling via CaMKII.

Diseased hearts have been shown to have a significant increase in nNOS mRNA and protein expression (Damy et al., 2004). While on the other hand, several studies have provided evidence that NO production by eNOS is markedly diminished in HF, and an overexpression of eNOS has been shown to relieve cardiac dysfunction in a mouse model of HF (Katz et al., 1999; Jones et al., 2003; Damy et al., 2004). Under normal physiological conditions eNOS appears to decrease $\beta$-adrenergic responsiveness via inhibition of LTCC (Wang et al., 2008), therefore a reduction in this mechanism may be an additional driving force for $\beta$-adrenergic driven arrhythmias under these conditions. The overall increase in nNOS activity in HF, and the potentially altered signaling activity and targets (for example caveolae-associated molecules versus the RyR) resulting from the translocation of this molecule to the sarcolemma, may be important for deleterious $\mathrm{Ca}^{2+}$ handling and arrhythmia formation (Damy et al., 2004). Additionally, in HF it appears that NO production inducible NOS (iNOS) becomes of increased importance, although the role of this is currently less defined (Massion et al., 2003; Carnicer et al., 2013).

The activity of cAMP/PKA is tightly regulation by the activity of specific phosphodiesterases (PDEs) and protein phosphatases, however, the distribution of these is out of the scope of the present manuscript (see Guellich et al., 2014 for a review on this matter).

Finally, it is important to consider that the relative contribution of the different subtypes of $\beta$-ARs may also contribute to the increased arrhythmogenic phenotype observed in HF. As noted previously distinct pathways are associated with the different subtypes. Previous work has shown that the $\beta_{1}$ subtype of adrenoreceptors are especially downregulated in $\mathrm{HF}$, while the coupling of the receptors to Gs, presumably via increased activity of the receptor kinases GRK2 and/or GRK5, is altered (Lohse et al., 2003). Interestingly, $\beta_{2}$-stimulation appears to be more arrhythmogenic in the failing heart when compared to the non-failing. Arrhythmogenesis appears to be driven by enhanced spontaneous SR $\mathrm{Ca}^{2+}$ release and aftercontractions, and is likely attributable, at least in part, to enhanced SR $\mathrm{Ca}^{2+}$ load secondary to PLB phosphorylation (DeSantiago et al., 2008). Away from the single cardiac myocyte, the requirement for $\beta$-Adrenergic stimulation to induce ectopic activity has also been shown in a human wedge preparation. Hearts from patients experiencing HF, exhibited ectopic beats and triggered activity in response to $\beta_{2}$-stimulation. The authors of this study ascribe the increase in arrhythmogenic activity due to the enhancement of transmural differences between $\mathrm{Ca}^{2+}$ and APD, facilitating the formation of DADs (Lang et al., 2015).

All of the data that has been discussed up till now has not considered the potential for regional differences in remodeling, which may be triggered by various stimuli, stresses and strains sensed at different anatomical locations. Taking this into account, a recent paper interestingly showed that in a porcine model 
of myocardial infarction and $\mathrm{HF}$, regional heterogeneities in arrhythmogenic remodeling do indeed exist. In this study, it was shown that changes in multiple currents lead to a shortening of AP at the border zone of the infarct, while APs recorded from the remote zone were prolonged. This will lead to a greater dispersion of repolarization across the ventricle, which could ultimately increase the arrhythmogenic substrate. Furthermore, these authors showed that cells isolated from the remote region showed DADs with a much higher frequency than in control, and amongst those cells, nearly half also showed triggered APs. Interestingly all HF-border cells showed DADs with over half showing triggered activity often with a superimposed EAD. In addition, inhibition of CaMKII decreased the occurrence of these DADs back to control levels, further indicating the importance of this multimodal signaling molecule in arrhythmia generation in this setting (Hegyi et al., 2018b). Although in this study these DADs were not induced by $\beta$-Adrenergic stimulation, but by burst pacing, one could also postulate that regional differences will also exist in terms of $\beta$-Adrenergic responsiveness in HF. In fact, a recent abstract from the Sipido group showed that in a pig model of MI, myocytes isolated from the peri-infarct region had a higher occurrence of isoproterenol induced DADs when compared to myocytes isolated from the region remote from the infarct (Dries et al., 2018b). These data pave the way for further research in this area.

\section{Local (Microdomain) Remodeling}

So far, we have only focussed on global remodeling, however, in addition to heterogeneity seen across the ventricular wall as just described, the myocyte in itself is not homogeneous, especially when the micro-architecture of the myocyte is altered as is seen in HF. For these reasons, we must also consider local subcellular alterations. Given the improvements in imaging techniques, and experimental advances over recent years we have gained greater insights into how alterations in these 'microdomains' may influence arrhythmogenic outcomes in HF. Over the next paragraphs, we will discuss a number of studies that have been carried out in an attempt to elucidate how these microdomains may influence stretch- or $\beta$-adrenergic-induced arrhythmia in $\mathrm{HF}$, with a view on targeted therapeutics (see the Section “Therapeutic Interventions").

As noted previously, $\mathrm{Ca}^{2+}$ entry via the LTCC is the initial trigger for $\mathrm{Ca}^{2+}$ release from the SR, therefore it is important to discuss potential changes in this current in HF. At a global level, the majority of studies have shown that there is no alteration in whole cell $\mathrm{Ca}^{2+}$ current recorded from myocytes from $\mathrm{HF}$ patients or in animal models, although single channel studies have shown that the availability and open probability of the LTCC is increased in human HF myocytes (Beuckelmann and Erdmann, 1992; Mukherjee and Spinale, 1998; Schröder et al., 1998). However, over recent years a number of interesting observations have come to light indicating the location of LTCCs are different in $\mathrm{HF}$ myocytes. Alteration in the location of the LTCC will also have detrimental effects on the levels of $\mathrm{Ca}^{2+}$ the individual channels are exposed to. Therefore, $\mathrm{Ca}^{2+}$ dependent inactivation of the current as well as the dynamic modulation of the window current are likely to be altered in
HF. Both of these changes will contribute to the formation of afterdepolarizations and can be influenced by $\beta$-adrenergic stimulation.

Using a rat model, combined with osmotic detubulation, Bryant et al. (2015) showed that although no differences in total $\mathrm{I}_{\mathrm{CaL}}$ density was seen between ventricular myocytes isolated from animals that had undergone a coronary artery ligation, this lack of change resulted from differential effects at the cell surface and the T-tubules. $\mathrm{I}_{\mathrm{CaL}}$ current density was decreased at the T-tubules while it was increased at the cell surface (Bryant et al., 2015).

An additional study from the group of Gorelik, using the super-resolution scanning patch-clamp technique showed similar findings. They elegantly showed that in both human and rat HF there was a redistribution of functional LTCCs from their physiological T-tubular location to the non-native crest of the sarcolemma. They went on to show that the open probability of these redistributed channels was dramatically increased, and the high open probability was linked to enhanced CaMKII modulation in the 'new' location. The current at these non-native channels resulted in an elevated $\mathrm{I}_{\mathrm{CaL}}$ window current, which contributed to the development of EADs. This remained true when these data were fedinto a 3-dimensional left ventricle model illustrating that the phenomenon occurring at the single cell level has far reaching arrhythmogenic implications (Sanchez-Alonso et al., 2016). Interestingly, work carried out over 20 years ago indicated that there was a frequency dependent decrease in $\mathrm{I}_{\mathrm{CaL}}$ in human dilated cardiomyopathy (Sipido et al., 1998). If this is to do with the altered LTCC microdomains, potentially due to CaMKII, remains to be seen, but should be the subject of future studies.

Localization of the LTCC to the T-tubules has previously been shown to be under control of the membrane scaffolding protein BIN1, with the knockdown of this protein leading to a reduction in surface LTCC and alterations in $\mathrm{Ca}^{2+}$ handling within the myocyte (Hong et al., 2010). Interestingly, BIN1 has been shown to be decreased in human $\mathrm{HF}$ as well as in a number of animal models, which may contribute to the alterations in patterns seen in LTCC localization (Hong et al., 2012; Caldwell et al., 2014). A more recent study has implicated that the $\beta$-adrenergic stimulation of BIN1 leads to reorganization of LTCC/RyR microdomains by also recruiting phosphorylated RyRs into the dyads. When BIN1 is downregulated, therefore, these phosphorylated RyRs may not be recruited in the dyad and arrhythmias may be promoted due to the defective $\mathrm{Ca}^{2+}$ handling (Fu et al., 2016).

Over 10 years ago, it was shown that in the failing heart there are a number of RyRs that become 'orphaned' from their LTCC counterpart in the T-tubule in spontaneously hypertensive rats (Song L.S. et al., 2006). These investigators used this model to show that this loss of coupling between the LTCC and RyR led to $\mathrm{Ca}^{2+}$ instability in the heart. More recently, Dries et al. (2018a) showed that in human myocytes isolated from HF patients, there were more noncoupled (to LTCC) RyRs which had more spontaneous activity than in non-HF. Hyperactivity of these non-coupled RyRs 
was reduced by CaMKII inhibition (Dries et al., 2018a). Previous work from the same group had illustrated that under healthy conditions, coupled (to LTCC) RyRs are distinctly modulated by CaMKII and ROS, while CaMKII and NOS1dependent modulation of RyRs during $\beta$-adrenergic stimulation was also restricted to the dyadic cleft (Dries et al., 2013, 2016). The authors went on to use a pig model to further investigate alterations in coupled and non-coupled RyRs and their regulation in normal and pathophysiological conditions. However, after an MI, it was shown that under adrenergic stimulation using isoproterenol, $\mathrm{Ca}^{2+}$ waves were frequent and originated at non-coupled sites, generating larger NCX currents than in sham operated animals. Inhibition of CaMKII or mitochondrial-ROS scavenging reduced spontaneous $\mathrm{Ca}^{2+}$ waves, and improved excitation-contraction coupling, indicating that these could be interesting therapeutic targets (Dries et al., 2018a). A very recent paper corroborated the arrhythmogenic role of mitochondrial ROS in the formation of arrhythmias in a guinea pig model of non-ischemic HF (Dey et al., 2018). In this model, continuous telemetry recordings indicated a high frequency of premature ventricular complexes and spontaneous ventricular tachycardia/ventricular fibrillation in animals after aortic constriction and isoproterenol stimulation. Scavenging mitochondrial ROS using MitoTEMPO markedly suppressed arrhythmias as well as blunting QT prolongation and reducing QT variability. Taken all together these data indicate specific targeting of one source of ROS is adequate to reduce proarrhythmic outcomes.

In addition to alterations seen in the LTCC/RyR microdomain, and the control thereof, that may influence arrhythmogenesis we also need to consider alterations in the distribution of the different $\beta$-ARs themselves. One of the first reports investigating potential alterations was by Nikolaev et al. (2010). In that seminal study it was shown that, as opposed to the situation in healthy myocytes where $\beta_{1}$-adrenergic receptors are widely distributed at the cell crest and $\beta_{2}$-receptors (and their associated signaling pathways) are localized to the T-tubules, in HF $\beta_{2}$-receptors were redistributed from the transverse tubules to the cell crest, leading to a change in $\beta_{2}$-receptors associated compartmentation of cAMP (Nikolaev et al., 2010). These alterations lead to the $\beta_{2}$-receptors acting more like $\beta_{1}$-receptors and have detrimental effects on the cross-talk of adrenergic signaling and $\mathrm{Ca}^{2+}$ handling within the failing cell. Follow up studies have shown that the compartmentalization of the cAMP signaling from $\beta_{2}$ receptors is governed by caveolin 3 , a protein that regulates the number of caveolae in the myocyte. Alteration in the T-tubule structure, levels of caveolin 3 and junctophilin 2 appear to be time-dependent, and gradually alter the $\beta_{2}$-signaling pathways. Furthermore, caveolin 3 overexpression in failing cells was able to restore, at least in part, the T-tubular location of the $\beta_{2}$-receptors (Wright et al., 2014; Schobesberger et al., 2017).

Interestingly, an additional study utilizing a rabbit model, also showed that reintroduction of caveolin-3 was able to normalizes $\beta$-adrenergic-induced contractile responses in $\mathrm{HF}$ myocytes, while also showing that in HF $\beta 2$-induced signaling gains access to myofilament which may contribute to abnormal PKA phosphorylation of troponin I and contractile dysfunction
(Barbagallo et al., 2016). In addition, work from the Sacconi group has shown that while cells from HF myocytes respond to $\beta$-adrenergic stimulation, this is not the case at the T-tubules that do not conduct APs, where the alterations seen in response may be caused by a lack of electrical activity. These data provide an alternative, or an additional, mechanism for the alterations seen in HF (Crocini et al., 2016).

\section{THERAPEUTIC INTERVENTIONS}

Despite advances in our knowledge of the pathophysiology underlying $\mathrm{HF}$ over the last 10 years, as outlined above, only a limited number of compounds have become available for the treatment of this debilitating disease (Gordin and Fonarow, 2016). Given the information in previous sections, we could consider targeting primary stressors (i.e., $\beta$-adrenergic stimulation or mechanical load) or downstream pathways. In Figure 3, we have summarized the most important mechanisms of afterdepolarizations, highlighting relationships between stimuli, key signaling molecules and targeted $\mathrm{Ca}^{2+}$ handling proteins and ion currents. Based on this scheme, we will discuss a number of (potential) interventions over the next few paragraphs that could be utilized to reduce the arrhythmogenic burden in HF patients.

\section{Targeting Mechanical Load and Structural Remodeling}

$\beta$-Blockers have been a mainstay of pharmacological treatment for $\mathrm{HF}$ for a number of years and are included in guidelines for treatment of $\mathrm{HF}$, in part due to their antiarrhythmic properties (Funck-Brentano, 2006; Ponikowski et al., 2016). In addition to a reduction in $\beta$-adrenergic signaling that will be directly caused by $\beta$-blockers, they will also lead to a reduction of mechanical stressors that may also be responsible for the efficacy of $\beta$-blockers in preventing sudden cardiac death.

Not all $\beta$-blockers are equal, however, with some being selective at adrenoreceptor subtypes while others have additional actions at other ion channels. For instance, the antiarrhythmic effects of propranolol have also been ascribed to the potential of this compound to block $\mathrm{Na}^{+}$channels (Fabritz et al., 2014). In long QT syndrome, for instance, it has been shown that propranolol has a significantly better QTc shortening effect compared to metoprolol and nadolol, and this led to a higher risk of cardiac events in symptomatic patients receiving metoprolol (Chockalingam et al., 2012). Therefore, given the information we currently have regarding the alteration in the number and location of subtypes of the $\beta$ - receptors in HF, specific targeting of $\beta$-ARs, perhaps differing over the course of HF progression, may offer an interesting solution.

An additional way that mechanical load can be reduced is by the used of LVADs. Previous work has shown that the use of a LVADs together with the use of a specific pharmacological regimen, including the use of $\beta$-blockers, can lead to the sustained reversal of severe $\mathrm{HF}$ secondary to non-ischemic cardiomyopathy, even when the LVAD is explanted (Birks et al., 2006). Interestingly, it appeared that the alterations seen in the 


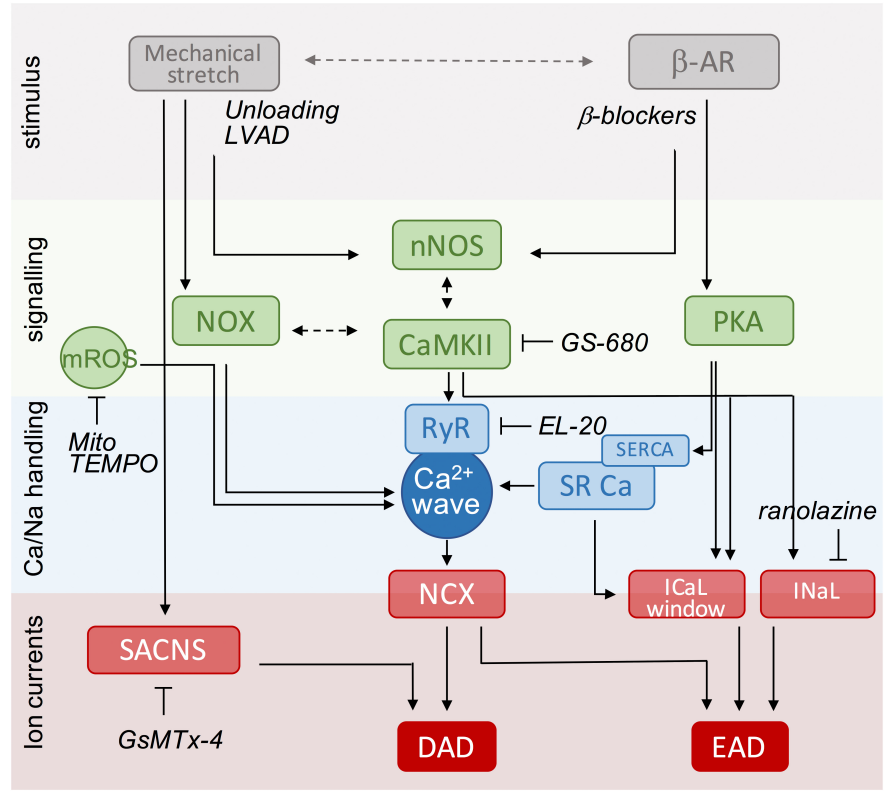

FIGURE 3 | Scheme of key events in $\beta$-adrenergic and stretch signaling for the induction of afterdepolarizations as potential targets for anti-arrhythmic therapy. The central event in the generation of afterdepolarizations is a $\mathrm{Ca}^{2+}$ wave that can produce DAD or EAD depending on the timing of NCX activation during the cardiac cycle (diastole or systole). Mechanical stretch and $\beta$-adrenergic agonists activate protein kinases (PKA, CaMKII) and free radicals (ROS, NO) that increase RyR activity and/or $\mathrm{SR} \mathrm{Ca}{ }^{2+}$ load to produce $\mathrm{Ca}^{2+}$ sparks and waves. Likewise, they increase the activity of late $\mathrm{Na}^{+}$and $\mathrm{Ca}^{2+}$ currents promoting EADs, directly via phosphorylation and redox modification, or indirectly via modulation by increased SR $\mathrm{Ca}^{2+}$ release secondary to enhanced $\mathrm{SR} \mathrm{Ca}^{2+}$ load. Stretch-activated ion channels further destabilize membrane potential during stretch. Anti-arrhythmic strategies include targeting of upstream stressors, downstream signaling components, and Ca handling proteins or currents. Specific examples under current investigation are indicated and further discussed in the text. DAD, delayed afterdepolarizations; EAD, early afterdepolarizations; LVAD, left ventricular assistant device; $\mathrm{NCX}, \mathrm{Na}^{+} / \mathrm{Ca}^{2+}$ exchanger; $\mathrm{NO}$, nitric oxide; NOX, NADPH oxidase type; nNOS, neuronal nitric oxide synthase; PKA, protein kinase A; ROS, reactive oxygen species; RyR, ryanodine receptor; SACNS, stretch-activated non-selective cation currents; SR, sarcoplasmic reticulum; SERCA, SR Ca ${ }^{2+}$-ATPase.

clinical phenotype in such patients was driven by modifications in ECC, and SR $\mathrm{Ca}^{2+}$ homeostasis in particular (Terracciano et al., 2004). More recent work has shown that mechanical unloading in a rat model (via heterotopic abdominal heart transplantation) reverses $\mathrm{T}$-tubule remodeling, and normalizes local $\mathrm{Ca}^{2+}$ handling (Ibrahim et al., 2012).

Cardiac resynchronization therapy (CRT) is an alternative approach to alter mechanical loading and stretch and will assist to resynchronize ventricular wall motion. A recent meta-analysis indicated that this intervention may significantly reduce the risk of ventricular arrhythmias when compared with patients receiving ICDs. Interestingly the same study also showed that patients who were not-responsive to CRT may have had a significantly higher risk of ventricular arrhythmias (Saini et al., 2016). Furthermore, it was also shown that CRT was able to efficiently reduce subcellular heterogeneity of structure and function of RyRs and T-tubules in a canine model of HF, potentially due to the restoration of ventricular synchrony ( $\mathrm{Li}$ et al., 2015).

Taking all of these data together it appears that alterations in mechanical load should be considered as a potential therapeutic strategy.

Another therapeutic strategy would be to potentially restrict remodeling in the first place. As previously mentioned, it appears there are a number of scaffolding proteins that are involved in the structural (and functional) remodeling of the $\mathrm{Ca}^{2+}$ microdomains in HF which could be the target for pharmaceutical intervention. For example, specific cardiac targeting of BIN1 could be an attractive option, although there are only limited data currently available and small molecules altering the activity of this protein are currently lacking. The potential for altering the T-tubule structure as a therapeutic intervention has recently been reviewed by Manfra et al. (2017).

\section{Direct Targeting}

It could also be possible to directly target proteins involved in arrhythmia formation under conditions of enhanced stretch or intense $\beta$-adrenergic stimulation. For example, the potential to target stretch activated channels was recently reviewed by White (2006), however, it is perhaps of note to mention GsMTx-4, which is a peptide isolated from tarantula venom. Mixed results have been obtained with GsMTx-4 to date, with one study showing the potential for reducing the number of premature ventricular beats in an ischemia/reperfusion mouse model, while an additional study indicated no benefit in a swine model (Barrabés et al., 2015; Wang et al., 2016). Further studies are required using this compound, and derivatives of it, to truly delineate the utility of inhibition of these channels in prevention of arrhythmogenesis in HF. 
Furthermore, the blockade of the components of $\mathrm{I}_{\mathrm{TI}}$ which actually contributes to afterdepolarization could also be an interesting target. Inhibition of NCX as a target has been discussed previously (Antoons et al., 2012), however, progress in this area has been hampered the lack by selective, and/or mode selective inhibitors. More recently a number of more selective agents have been developed, including ORM10103 which have shown their utility in preventing $\mathrm{Ca}^{2+}$ overload induced arrhythmias (Nagy et al., 2014). However, in a rabbit HF model NCX inhibition with ORM-10103 reduced premature ventricular beats but was unable to suppress secondary $\mathrm{Ca}^{2+}$ rise or the occurrence of EADs (Chang et al., 2018).

Direct inhibition of 'leaky' RyRs could also be an interesting target to diminish proarrhythmic $\mathrm{Ca}^{2+}$ leak. A recent paper showed the utility of a tetracaine-derived compound, EL20, which was able to limit arrhythmogenic $\mathrm{Ca}^{2+}$ waves in a CPVT model by only limiting $\mathrm{Ca}^{2+}$ release from RyRs associated with calmodulin (Klipp et al., 2018). Should this have utility in HF should be the subject of further investigation.

An alternative approach would be to alter the activity of SERCA in HF. A number of pre-clinical studies showed that there was anti-arrhythmic potential for increasing SERCA activity in HF using adeno-associated virus technology (Kawase et al., 2008; Lyon et al., 2011). Despite initial positive outcomes in small trials (Jessup et al., 2011), larger clinical trials have been unable to show the benefit of this approach (Greenberg et al., 2016; Hulot et al., 2017). Despite these disappointing results, further studies are still required to investigate the true utility of this approach. Activation of SERCA using small molecules may also be potentially interesting approach, and recently istaroxime has become a compound of interest (Ferrandi et al., 2013). A clinical trial using this compound is currently ongoing (ClinicalTrials.gov Identifier: NCT02617446) with the results being highly anticipated.

\section{Targeting Downstream Modulation}

An alternative avenue would be to target downstream signaling pathways that are involved. Perhaps one of the most investigated of these is the CaMKII pathway, perhaps due to the multimodal action of this kinase, and the fact that targeting this molecule may lead to selective modulation of proarrhythmic RyRs (Dries et al., 2018a). Interestingly it was recently shown that CaMKII activity persists even during chronic $\beta$-adrenergic blockade in $\mathrm{HF}$, indicating that these two pathways could be targeted independently (Dewenter et al., 2017). To date, however, there are no clinically available CaMKII inhibitors, likely due to the lack of selective, bioavailable compounds. There are numerous reviews dealing with the potential of CaMKII inhibition as a potential treatment for $\mathrm{HF}$, and for those reasons we will only discuss a couple of newer studies that have added fuel to the fire regarding the use of CaMKII inhibitors as antiarrhythmics (Swaminathan et al., 2012; Fischer et al., 2013; Westenbrink et al., 2013).
A recent study utilized the novel agent, GS-680, which is an ATP-dependent small molecule inhibitor of CaMKII, which appears to have good selectivity for CaMKII. In this study, this compound did not impair contractile function in failing human ventricular trabeculae and blunted the negative force-frequency relationship. Meanwhile, it increased the $\mathrm{Ca}^{2+}$ transient amplitude in isolated failing ventricular myocytes and reduced premature atrial contractions and afterdepolarizations in atrial cardiomyocytes (Lebek et al., 2018). Additionally, Dries et al. (2018a) recently showed that the specific CaMKII peptide inhibitor (AIP) significantly reduced the hyperactivity of RyRs in non-coupled regions without affecting spark frequency at coupled sites (Dries et al., 2018a). Finally, it has also been shown that inhibition of CaMKII is able to reduce the proarrhythmic effects of PDE-inhibitors, which act by increasing pools of cAMP (Bobin et al., 2016). If this is also true in HF should be the subject of future studies. If CaMKII inhibition will eventually function as an effective antiarrhythmic in HF still remains to be seen. While discussing CaMKII, it is also important to discuss the late $\mathrm{Na}^{+}$ current. Recent work has shown that inhibition of this current is able to suppress $\mathrm{Ca}^{2+}$ related arrhythmias by reducing CaMKII phosphorylation (Wei et al., 2017). Furthermore, ranolazine, an agent that inhibits both late $\mathrm{Na}^{+}$and $\mathrm{K}^{+}$channels has been shown to have antiarrhythmic effects in the intact heart in $\mathrm{CHF}$ and, interestingly, was not associated with drug-induced proarrhythmia (Frommeyer et al., 2012). Once again, further work is required to determine the true utility of late $\mathrm{Na}^{+}$current inhibition under these circumstances.

Reactive oxygen species is one of the determinants of CaMKII activity, as well as having direct effects on $\mathrm{Ca}^{2+}$ handling proteins directly, so perhaps it is also possible to target ROS sources as an antiarrhythmic intervention. Interestingly the positive effect of the antioxidant vitamin $\mathrm{C}$ on the $\beta$-adrenergic response to dobutamine was blunted in HF patients, perhaps due to the global antioxidant properties of this agent (Mak and Newton, 2004), leading us to believe that a targeted approach may be required. The inhibition of NOX2 may be a promising approach although it may be necessary to avoid concurrent inhibition of other NADPHs which are required in other organ systems (Sag et al., 2014). Furthermore, supplementing with BH4, to 'recouple' uncoupled NOS has been proposed (Moens et al., 2008), however, there have been issues with the bio-availability of this compound (see Bendall et al., 2014). The final source of ROS that could be an interesting target in mitochondrial ROS, and as noted earlier a number of studies have shown the utility of mitoTEMPO in reducing arrhythmia in HF (Dey et al., 2018; Dries et al., 2018a). The development of bioavailable safe tools to directly alter mitochondrial ROS production is still in its infancy and efforts should be concentrated to develop these.

Finally, targeting Epac has also been proposed as a potential target for arrhythmias driven by $\beta$-adrenergic stimulation, although there is discussion about its role. A recent study showed that treatment with an Epac activator, 8-CPT, enhanced the late $\mathrm{Na}^{+}$current while inhibition of PKA (via PKI) did not affect the catecholamine induced increases in late $\mathrm{Na}^{+}$ current, indicating that Epac alone plays a crucial role in these arrhythmias (Dybkova et al., 2014; Fujita et al., 2017). 


\section{CONCLUDING REMARKS}

We still have a long way to go in treating ventricular arrhythmias that occur as a result of HF, however, concentrating on various microdomains within the cardiac myocytes that are under control of multiple pathways could be of great interest. Furthermore, linking the potential electro-mechanical and mechano-electro feedback loops could aid us in treating arrhythmias that occur as a result of this debilitating disease.

Is stretch sympathetic to HF? Only time and research will fully answer this question, but in the mean time we will have to be.

\section{REFERENCES}

Acsai, K., Antoons, G., Livshitz, L., Rudy, Y., and Sipido, K. R. (2011). Microdomain $\left[\mathrm{Ca}^{+}{ }^{+}\right.$near ryanodine receptors as reported by $\mathrm{L}$-type $\mathrm{Ca} 2^{+}$and $\mathrm{Na}^{+} / \mathrm{Ca} 2^{+}$exchange currents. J. Physiol. 589, 2569-2583. doi: 10.1113/jphysiol. 2010.202663

Ahern, G. P., Hsu, S.-F., Klyachko, V. A., and Jackson, M. B. (2000). Induction of persistent sodium current by exogenous and endogenous nitric oxide. J. Biol. Chem. 275, 28810-28815. doi: 10.1074/jbc.M003090200

Allen, D. G., and Kurihara, S. (1982). The effects of muscle length on intracellular calcium transients in mammalian cardiac muscle. J. Physiol. 327, 79-94. doi: 10.1113/jphysiol.1982.sp014221

Antoons, G., Johnson, D. M., Dries, E., Santiago, D. J., Ozdemir, S., Lenaerts, I., et al. (2015). Calcium release near l-type calcium channels promotes beat-tobeat variability in ventricular myocytes from the chronic AV block dog. J. Mol. Cell. Cardiol. 89(Part B), 326-334. doi: 10.1016/j.yjmcc.2015.10.008

Antoons, G., Volders, P. G., Stankovicova, T., Bito, V., Stengl, M., Vos, M. A., et al. (2007). Window $\mathrm{Ca} 2^{+}$current and its modulation by $\mathrm{Ca} 2^{+}$release in hypertrophied cardiac myocytes from dogs with chronic atrioventricular block. J. Physiol. 579, 147-160. doi: 10.1113/jphysiol.2006.124222

Antoons, G., Willems, R., and Sipido, K. R. (2012). Alternative strategies in arrhythmia therapy: evaluation of $\mathrm{Na} / \mathrm{Ca}$ exchange as an anti-arrhythmic target. Pharmacol. Ther. 134, 26-42. doi: 10.1016/j.pharmthera.2011.12.001

Barbagallo, F., Xu, B., Reddy, G. R., West, T., Wang, Q., Fu, Q., et al. (2016). Genetically encoded biosensors reveal PKA hyperphosphorylation on the myofilaments in rabbit heart failure. Circ. Res. 119, 931-943. doi: 10.1161/ CIRCRESAHA.116.308964

Barouch, L. A., Harrison, R. W., Skaf, M. W., Rosas, G. O., Cappola, T. P., Kobeissi, Z. A., et al. (2002). Nitric oxide regulates the heart by spatial confinement of nitric oxide synthase isoforms. Nature 416, 337-339. doi: 10.1038/416005a

Barrabés, J. A., Inserte, J., Agulló, L., Rodríguez-Sinovas, A., Alburquerque-Béjar, J. J., and Garcia-Dorado, D. (2015). Effects of the selective stretch-activated channel blocker GsMtx4 on stretch-induced changes in refractoriness in isolated rat hearts and on ventricular premature beats and arrhythmias after coronary occlusion in swine. PLoS One 10:e0125753. doi: 10.1371/journal.pone. 0125753

Bendall, J. K., Douglas, G., McNeill, E., Channon, K. M., and Crabtree, M. J. (2014). Tetrahydrobiopterin in cardiovascular health and disease. Antioxid. Redox Signal. 20, 3040-3077. doi: 10.1089/ars.2013.5566

Bers, D. M. (2002). Cardiac excitation-contraction coupling. Nature 415, 198-205. doi: $10.1038 / 415198 \mathrm{a}$

Bers, D. M., and Morotti, S. (2014). Ca2 ${ }^{+}$current facilitation is CaMKII-dependent and has arrhythmogenic consequences. Front. Pharmacol. 5:144. doi: 10.3389/ fphar.2014.00144

Beuckelmann, D. J., and Erdmann, E. (1992). Ca2 ${ }^{+}$-currents and intracellular $\left[\mathrm{Ca}^{+}\right]$i-transients in single ventricular myocytes isolated from terminally failing human myocardium. Basic Res. Cardiol. 87(Suppl. 1), 235-243.

Beuckelmann, D. J., Näbauer, M., and Erdmann, E. (1993). Alterations of $\mathrm{K}^{+}$ currents in isolated human ventricular myocytes from patients with terminal heart failure. Circ. Res. 73, 379-385. doi: 10.1161/01.RES.73.2.379

Biesmans, L., Macquaide, N., Heinzel, F. R., Bito, V., Smith, G. L., and Sipido, K. R. (2011). Subcellular heterogeneity of ryanodine receptor properties in

\section{AUTHOR CONTRIBUTIONS}

Both authors contributed to manuscript preparation and approved the final version of the manuscript.

\section{ACKNOWLEDGMENTS}

The authors would like to thank Roel Spätjens for the assistance in the preparation of Figure $\mathbf{1}$ and Patrick Schönleitner for the assistance in the preparation of Figure 2.

ventricular myocytes with low T-tubule density. PLoS One 6:e25100. doi: 10. 1371/journal.pone.0025100

Birks, E. J., Tansley, P. D., Hardy, J., George, R. S., Bowles, C. T., Burke, M., et al. (2006). Left ventricular assist device and drug therapy for the reversal of heart failure. N. Engl. J. Med. 355, 1873-1884. doi: 10.1056/NEJMoa0 53063

Bobin, P., Varin, A., Lefebvre, F., Fischmeister, R., Vandecasteele, G., and Leroy, J. (2016). Calmodulin kinase II inhibition limits the pro-arrhythmic $\mathrm{Ca}_{2}{ }^{+}$waves induced by cAMP-phosphodiesterase inhibitors. Cardiovasc. Res. 110, 151-161. doi: $10.1093 / \mathrm{cvr} / \mathrm{cvw} 027$

Bristow, M. R., Ginsburg, R., Minobe, W., Cubicciotti, R. S., Sageman, W. S., Lurie, K., et al. (1982). Decreased catecholamine sensitivity and betaadrenergic-receptor density in failing human hearts. N. Engl. J. Med. 307, 205-211. doi: 10.1056/NEJM198207223070401

Bryant, S. M., Kong, C. H., Watson, J., Cannell, M. B., James, A. F., and Orchard, C. H. (2015). Altered distribution of ICa impairs Ca release at the t-tubules of ventricular myocytes from failing hearts. J. Mol. Cell. Cardiol. 86, 23-31. doi: 10.1016/j.yjmcc.2015.06.012

Burger, D. E., Lu, X., Lei, M., Xiang, F.-L., Hammoud, L., Jiang, M., et al. (2009). Neuronal nitric oxide synthase protects against myocardial infarction-induced ventricular arrhythmia and mortality in mice. Circulation 120, 1345-1354. doi: 10.1161/CIRCULATIONAHA.108.846402

Burgoyne, J. R., Mongue-Din, H., Eaton, P., and Shah, A. M. (2012). Redox signaling in cardiac physiology and pathology. Circ. Res. 111, 1091-1106. doi: 10.1161/CIRCRESAHA.111.255216

Calaghan, S. C., Le Guennec, J.-Y., and White, E. (2004). Cytoskeletal modulation of electrical and mechanical activity in cardiac myocytes. Prog. Biophys. Mol. Biol. 84, 29-59. doi: 10.1016/S0079-6107(03)00057-9

Caldwell, J. L., Smith, C. E., Taylor, R. F., Kitmitto, A., Eisner, D. A., Dibb, K. M., et al. (2014). Dependence of cardiac transverse tubules on the BAR domain protein amphiphysin II (BIN-1). Circ. Res. 115, 986-996. doi: 10.1161/ CIRCRESAHA.116.303448

Cannell, M. B., and Kong, C. H. (2012). Local control in cardiac E-C coupling. J. Mol. Cell. Cardiol. 52, 298-303. doi: 10.1016/j.yjmcc.2011.04.014

Carnicer, R., Crabtree, M. J., Sivakumaran, V., Casadei, B., and Kass, D. A. (2013). Nitric oxide synthases in heart failure. Antioxid. Redox Signal. 18, 1078-1099. doi: 10.1089/ars.2012.4824

Carnicer, R., Suffredini, S., Liu, X., Reilly, S., Simon, J. N., Surdo, N. C., et al. (2017). The subcellular localisation of neuronal nitric oxide synthase determines the downstream effects of no on myocardial function. Cardiovasc. Res. doi: 10.1093/ cvr/cvx002 [Epub ahead of print].

Catterall, W. A. (2015). Regulation of cardiac calcium channels in the fight-or-flight response. Curr. Mol. Pharmacol. 8, 12-21. doi: 10.2174/ 1874467208666150507103417

Cerrone, M., Colombi, B., Santoro, M., di Barletta, M. R., Scelsi, M., Villani, L., et al. (2005). Bidirectional ventricular tachycardia and fibrillation elicited in a knock-in mouse model carrier of a mutation in the cardiac ryanodine receptor. Circ. Res. 96, e77-e82. doi: 10.1161/01.RES.0000169067.51055.72

Cerrone, M., Napolitano, C., and Priori, S. G. (2009). Catecholaminergic polymorphic ventricular tachycardia: a paradigm to understand mechanisms of arrhythmias associated to impaired $\mathrm{Ca}^{+}{ }^{+}$regulation. Heart Rhythm 6, 1652-1659. doi: 10.1016/j.hrthm.2009.06.033 
Cerrone, M., Noujaim, S. F., Tolkacheva, E. G., Talkachou, A., O’Connell, R., Berenfeld, O., et al. (2007). Arrhythmogenic mechanisms in a mouse model of catecholaminergic polymorphic ventricular tachycardia. Circ. Res. 101, 10391048. doi: 10.1161/CIRCRESAHA.107.148064

Chang, P.-C., Lu, Y.-Y., Lee, H.-L., Lin, S.-F., Chu, Y., Wen, M.-S., et al. (2018). Paradoxical effects of sodium-calcium exchanger inhibition on torsade de pointes and early afterdepolarization in a heart failure rabbit model. J. Cardiovasc. Pharmacol. 72, 97-105. doi: 10.1097/FJC.00000000000 00598

Chen, W.-W., Xiong, X.-Q., Chen, Q., Li, Y.-H., Kang, Y.-M., and Zhu, G.-Q. (2015). Cardiac sympathetic afferent reflex and its implications for sympathetic activation in chronic heart failure and hypertension. Acta Physiol. 213, 778-794. doi: 10.1111/apha.12447

Cheng, H., and Lederer, W. J. (2008). Calcium sparks. Physiol. Rev. 88, 1491-1545. doi: 10.1152 /physrev.00030.2007

Chen-Izu, Y., and Izu, L. T. (2017). Mechano-chemo-transduction in cardiac myocytes. J. Physiol. 595, 3949-3958. doi: 10.1113/JP273101

Chidsey, C. A., Braunwald, E., Morrow, A. G., and Mason, D. T. (1963). Myocardial norepinephrine concentration in man. effects of reserpine and of congestive heart failure. N. Engl. J. Med. 269, 653-658. doi: 10.1056/ NEJM196309262691302

Chockalingam, P., Crotti, L., Girardengo, G., Johnson, J. N., Harris, K. M., van der Heijden, J. F., et al. (2012). Not all beta-blockers are equal in the management of long QT syndrome types 1 and 2: higher recurrence of events under metoprolol. J. Am. Coll. Cardiol. 60, 2092-2099. doi: 10.1016/j.jacc.2012.07.046

Cingolani, H. E., Pérez, N. G., Cingolani, O. H., and Ennis, I. L. (2013). The Anrep effect: 100 years later. Am. J. Physiol. Heart Circ. Physiol. 304, H175-H182. doi: 10.1152/ajpheart.00508.2012

Cohn, J. N., Ferrari, R., Sharpe, N., and on Behalf of an International Forum on Cardiac Remodeling (2000). Cardiac remodeling-concepts and clinical implications: a consensus paper from an international forum on cardiac remodeling. J. Am. Coll. Cardiol. 35, 569-582. doi: 10.1016/S0735-1097(99) 00630-0

Coste, B., Mathur, J., Schmidt, M., Earley, T. J., Ranade, S., Petrus, M. J., et al. (2010). Piezol and Piezo2 are essential components of distinct mechanically activated cation channels. Science 330, 55-60. doi: 10.1126/science.1193270

Craelius, W., Chen, V., and el-Sherif, N. (1988). Stretch activated ion channels in ventricular myocytes. Biosci. Rep. 8, 407-414. doi: 10.1007/BF01121637

Cranefield, P. F. (1977). Action potentials, afterpotentials, and arrhythmias. Circ. Res. 41, 415-423. doi: 10.1161/01.RES.41.4.415

Crocini, C., Coppini, R., Ferrantini, C., Yan, P., Loew, L. M., Poggesi, C., et al. (2016). T-tubular electrical defects contribute to blunted $\beta$-adrenergic response in heart failure. Int. J. Mol. Sci. 17:E1471. doi: 10.3390/ijms17091471

Curran, J., Hinton, M. J., Ríos, E., Bers, D. M., and Shannon, T. R. (2007). $\beta$-adrenergic enhancement of sarcoplasmic reticulum calcium leak in cardiac myocytes is mediated by calcium/calmodulin-dependent protein kinase. Circ. Res. 100, 391-398. doi: 10.1161/01.RES.0000258172.74570.e6

Curran, J., Tang, L., Roof, S. R., Velmurugan, S., Millard, A., Shonts, S., et al. (2014). Nitric oxide-dependent activation of CaMKII increases diastolic sarcoplasmic reticulum calcium release in cardiac myocytes in response to adrenergic stimulation. PLoS One 9:e87495. doi: 10.1371/journal.pone.0087495

Damy, T., Ratajczak, P., Shah, A. M., Camors, E., Marty, I., Hasenfuss, G., et al. (2004). Increased neuronal nitric oxide synthase-derived NO production in the failing human heart. Lancet 363, 1365-1367. doi: 10.1016/S0140-6736(04) 16048-0

Dangman, K. H., Danilo, P., Hordof, A. J., Mary-Rabine, L., Reder, R. F., and Rosen, M. R. (1982). Electrophysiologic characteristics of human ventricular and Purkinje fibers. Circulation 65, 362-368. doi: 10.1161/01.CIR.65.2.362

DeSantiago, J., Ai, X., Islam, M., Acuna, G., Ziolo, M. T., Bers, D. M., et al. (2008). Arrhythmogenic effects of $\beta 2$-adrenergic stimulation in the failing heart are attributable to enhanced sarcoplasmic reticulum Ca load. Circ. Res. 102, 1389-1397. doi: 10.1161/CIRCRESAHA.107.169011

Dewenter, M., Neef, S., Vettel, C., Lämmle, S., Beushausen, C., Zelarayan, L. C., et al. (2017). Calcium/calmodulin-dependent protein kinase II activity persists during chronic $\beta$-adrenoceptor blockade in experimental and human heart failureclinical perspective. Circ. Heart Fail. 10:e003840. doi: 10.1161/ CIRCHEARTFAILURE.117.003840
Dey, S., DeMazumder, D., Sidor, A., Foster, D. B., and O'Rourke, B. (2018). Mitochondrial ROS drive sudden cardiac death and chronic proteome remodeling in heart failure. Circ. Res. 123, 356-371. doi: 10.1161/ CIRCRESAHA.118.312708

Dobrev, D., and Wehrens, X. H. (2014). Role of RyR2 phosphorylation in heart failure and arrhythmias: controversies around ryanodine receptor phosphorylation in cardiac disease. Circ. Res. 114, 1311-1319. doi: 10.1161/ CIRCRESAHA.114.300568

Doleschal, B., Primessnig, U., Wölkart, G., Wolf, S., Schernthaner, M., Lichtenegger, M., et al. (2015). TRPC3 contributes to regulation of cardiac contractility and arrhythmogenesis by dynamic interaction with NCX1. Cardiovasc. Res. 106, 163-173. doi: 10.1093/cvr/cvv022

Dries, E., Bito, V., Lenaerts, I., Antoons, G., Sipido, K. R., and Macquaide, N. (2013). Selective modulation of coupled ryanodine receptors during microdomain activation of calcium/calmodulin-dependent kinase II in the dyadic cleft. Circ. Res. 113, 1242-1252. doi: 10.1161/CIRCRESAHA.113.301896

Dries, E., Santiago, D. J., Gilbert, G., Lenaerts, I., Vandenberk, B., Nagaraju, C. K., et al. (2018a). Hyperactive ryanodine receptors in human heart failure and ischemic cardiomyopathy reside outside of couplons. Cardiovasc. Res. 114, 1512-1524. doi: 10.1093/cvr/cvy088

Dries, E., Vandenberk, B., Gilbert, G., Amoni, M., Holemans, P., Willems, R., et al. (2018b). P519Regional heterogeneity of hyperactive non-coupled ryanodine receptors makes the peri-infarct region more prone to triggered activities after myocardial infarction. Cardiovasc. Res. 114, S126-S127. doi: 10.1093/cvr/ cry060.376

Dries, E., Santiago, D. J., Johnson, D. M., Gilbert, G., Holemans, P., Korte, S. M., et al. (2016). Calcium/calmodulin-dependent kinase II and nitric oxide synthase 1-dependent modulation of ryanodine receptors during $\beta$-adrenergic stimulation is restricted to the dyadic cleft. J. Physiol. 594, 5923-5939. doi: 10.1113/JP271965

Dybkova, N., Wagner, S., Backs, J., Hund, T. J., Mohler, P. J., Sowa, T., et al. (2014). Tubulin polymerization disrupts cardiac $\beta$-adrenergic regulation of late INa. Cardiovasc. Res. 103, 168-177. doi: 10.1093/cvr/cvu120

Eckberg, D. L., Drabinsky, M., and Braunwald, E. (1971). Defective cardiac parasympathetic control in patients with heart disease. N. Engl. J. Med. 285, 877-883. doi: 10.1056/NEJM197110142851602

Eder, P., and Molkentin, J. D. (2011). TRPC channels as effectors of cardiac hypertrophy. Circ. Res. 108, 265-272. doi: 10.1161/CIRCRESAHA.110.225888

Erickson, J. R., Joiner, M. A., Guan, X., Kutschke, W., Yang, J., Oddis, C. V., et al. (2008). A dynamic pathway for calcium-independent activation of CaMKII by methionine oxidation. Cell 133, 462-474. doi: 10.1016/j.cell.2008.02.048

Fabritz, L., Franz, M. R., Carmeliet, E., and Kirchhof, P. (2014). To the EditorPropranolol, a $\beta$-adrenoreceptor blocker, prevents arrhythmias also by its sodium channel blocking effect. Heart Rhythm 11:e1. doi: 10.1016/j.hrthm.2013. 12.027

Faggioni, M., Hwang, H. S., van der Werf, C., Nederend, I., Kannankeril, P. J., Wilde, A. A., et al. (2013). Accelerated sinus rhythm prevents catecholaminergic polymorphic ventricular tachycardia in mice and in patients. Circ. Res. 112, 689-697. doi: 10.1161/CIRCRESAHA.111.300076

Farah, C., Michel, L. Y. M., and Balligand, J.-L. (2018). Nitric oxide signalling in cardiovascular health and disease. Nat. Rev. Cardiol. 15, 292-316. doi: 10.1038/ nrcardio.2017.224

Fedida, D., Noble, D., Rankin, A. C., and Spindler, A. J. (1987). The arrhythmogenic transient inward current iTI and related contraction in isolated guinea-pig ventricular myocytes. J. Physiol. 392, 523-542. doi: 10.1113/jphysiol.1987. sp016795

Fernández-Velasco, M., Rueda, A., Rizzi, N., Benitah, J.-P., Colombi, B., Napolitano, C., et al. (2009). Increased $\mathrm{Ca}^{+}{ }^{+}$sensitivity of the ryanodine receptor mutant RyR2R4496C underlies catecholaminergic polymorphic ventricular tachycardia. Circ. Res. 104, 201-209. doi: 10.1161/CIRCRESAHA. 108.177493

Ferrandi, M., Barassi, P., Tadini-Buoninsegni, F., Bartolommei, G., Molinari, I., Tripodi, M. G., et al. (2013). Istaroxime stimulates SERCA2a and accelerates calcium cycling in heart failure by relieving phospholamban inhibition. Br. J. Pharmacol. 169, 1849-1861. doi: 10.1111/bph.12278

Fink, M., Noble, P. J., and Noble, D. (2011). Ca2 ${ }^{+}$-induced delayed afterdepolarizations are triggered by dyadic subspace $\mathrm{Ca} 2^{+}$affirming that 
increasing SERCA reduces aftercontractions. Am. J. Physiol. Heart Circ. Physiol. 301, H921-H935. doi: 10.1152/ajpheart.01055.2010

Fischer, T. H., Neef, S., and Maier, L. S. (2013). The Ca-calmodulin dependent kinase II: a promising target for future antiarrhythmic therapies? J. Mol. Cell. Cardiol. 58, 182-187. doi: 10.1016/j.yjmcc.2012.11.003

Florea, V. G., Mareyev, V. Y., Samko, A. N., Orlova, I. A., Coats, A. J., and Belenkov, Y. N. (1999). Left ventricular remodelling: common process in patients with different primary myocardial disorders. Int. J. Cardiol. 68, 281-287. doi: 10. 1016/S0167-5273(98)00362-3

Forbes, M. S., and Sperelakis, N. (1983). The membrane systems and cytoskeletal elements of mammalian myocardial cells. Cell Muscle Motil. 3, 89-155. doi: 10.1007/978-1-4615-9296-9_5

Fowler, E. D., Kong, C. H. T., Hancox, J. C., and Cannell, M. B. (2018). Late $\mathrm{Ca}_{2}{ }^{+}$sparks and ripples during the systolic $\mathrm{Ca} 2^{+}$transient in heart muscle cellsnovelty and significance. Circ. Res. 122, 473-478. doi: 10.1161/ CIRCRESAHA.117.312257

Franz, M. R., Burkhoff, D., Yue, D. T., and Sagawa, K. (1989). Mechanically induced action potential changes and arrhythmia in isolated and in situ canine hearts. Cardiovasc. Res. 23, 213-223. doi: 10.1093/cvr/23.3.213

Frisk, M., Ruud, M., Espe, E. K. S., Aronsen, J. M., Røe, Å. T., Zhang, L., et al. (2016). Elevated ventricular wall stress disrupts cardiomyocyte t-tubule structure and calcium homeostasis. Cardiovasc. Res. 112, 443-451. doi: 10.1093/cvr/cvw111

Frommeyer, G., Rajamani, S., Grundmann, F., Stypmann, J., Osada, N., Breithardt, G., et al. (2012). New insights into the beneficial electrophysiologic profile of ranolazine in heart failure: prevention of ventricular fibrillation with increased postrepolarization refractoriness and without drug-induced proarrhythmia. J. Card. Fail. 18, 939-949. doi: 10.1016/j.cardfail.2012.10.017

Fu, Y., Shaw, S. A., Naami, R., Vuong, C. L., Basheer, W. A., Guo, X., et al. (2016). Isoproterenol promotes rapid ryanodine receptor movement to bridging integrator 1 (BIN1)-organized dyads. Circulation 133, 388-397. doi: 10.1161/ CIRCULATIONAHA.115.018535

Fujita, T., Umemura, M., Yokoyama, U., Okumura, S., and Ishikawa, Y. (2017). The role of Epac in the heart. Cell. Mol. Life Sci. 74, 591-606. doi: 10.1007/s00018016-2336-5

Funck-Brentano, C. (2006). Beta-blockade in CHF: from contraindication to indication. Eur. Heart J. Suppl. 8, C19-C27. doi: 10.1093/eurheartj/sul010

Garan, A. R., Yuzefpolskaya, M., Colombo, P. C., Morrow, J. P., Te-Frey, R., Dano, D., et al. (2013). Ventricular arrhythmias and implantable cardioverterdefibrillator therapy in patients with continuous-flow left ventricular assist devices. J. Am. Coll. Cardiol. 61, 2542-2550. doi: 10.1016/j.jacc.2013.04.020

Gill, J. S., McKenna, W. J., and Camm, A. J. (1995). Free radicals irreversibly decrease $\mathrm{Ca}_{2}{ }^{+}$currents in isolated guinea-pig ventricular myocytes. Eur. J. Pharmacol. 292, 337-340.

Gómez, A. M., Ruiz-Hurtado, G., Benitah, J.-P., and DomínguezRodríguez, A. (2013). $\mathrm{Ca}\left(2^{+}\right)$fluxes involvement in gene expression during cardiac hypertrophy. Curr. Vasc. Pharmacol. 11, 497-506. doi: 10.2174/1570161111311040013

González, D. R., Fernández, I. C., Ordenes, P. P., Treuer, A. V., Eller, G., and Boric, M. P. (2008). Differential role of S-nitrosylation and the NO-cGMP-PKG pathway in cardiac contractility. Nitric Oxide 18, 157-167. doi: 10.1016/j.niox. 2007.09.086

Gordin, J. S., and Fonarow, G. C. (2016). New medications for heart failure. Trends Cardiovasc. Med. 26, 485-492. doi: 10.1016/j.tcm.2016.02.008

Gottlieb, P., Folgering, J., Maroto, R., Raso, A., Wood, T. G., Kurosky, A., et al. (2008). Revisiting TRPC1 and TRPC6 mechanosensitivity. Pflugers Arch. 455, 1097-1103. doi: 10.1007/s00424-007-0359-3

Gottlieb, P. A. (2017). A tour de force: the discovery, properties, and function of piezo channels. Curr. Top. Membr. 79, 1-36. doi: 10.1016/bs.ctm.2016. 11.007

Greenberg, B., Butler, J., Felker, G. M., Ponikowski, P., Voors, A. A., Desai, A. S., et al. (2016). Calcium upregulation by percutaneous administration of gene therapy in patients with cardiac disease (CUPID 2): a randomised, multinational, double-blind, placebo-controlled, phase $2 \mathrm{~b}$ trial. Lancet 387 , 1178-1186. doi: 10.1016/S0140-6736(16)00082-9

Guellich, A., Mehel, H., and Fischmeister, R. (2014). Cyclic AMP synthesis and hydrolysis in the normal and failing heart. Pflugers Arch. 466, 1163-1175. doi: 10.1007/s00424-014-1515-1
Guo, A., Zhang, C., Wei, S., Chen, B., and Song, L.-S. (2013). Emerging mechanisms of T-tubule remodelling in heart failure. Cardiovasc. Res. 98, 204-215. doi: $10.1093 / \mathrm{cvr} / \mathrm{cvt} 020$

Guo, J., and Duff, H. J. (2006). Calmodulin kinase II accelerates L-type Ca2 ${ }^{+}$ current recovery from inactivation and compensates for the direct inhibitory effect of $\left[\mathrm{Ca}^{+}\right]$i in rat ventricular myocytes. J. Physiol. 574, 509-518. doi: 10.1113/jphysiol.2006.109199

Guo, T., Zhang, T., Ginsburg, K. S., Mishra, S., Brown, J. H., and Bers, D. M. (2012). CaMKII $\mathrm{C}$ slows [Ca]i decline in cardiac myocytes by promoting Ca sparks. Biophys. J. 102, 2461-2470. doi: 10.1016/j.bpj.2012.04.015

Gutierrez, D. A., Fernandez-Tenorio, M., Ogrodnik, J., and Niggli, E. (2013). NO-dependent CaMKII activation during $\beta$-adrenergic stimulation of cardiac muscle. Cardiovasc. Res. 100, 392-401. doi: 10.1093/cvr/cvt201

Hansen, D. E., Craig, C. S., and Hondeghem, L. M. (1990). Stretch-induced arrhythmias in the isolated canine ventricle. Evidence for the importance of mechanoelectrical feedback. Circulation 81, 1094-1105. doi: 10.1161/01.CIR.81. 3.1094

Hartmann, N., Pabel, S., Herting, J., Schatter, F., Renner, A., Gummert, J., et al. (2017). Antiarrhythmic effects of dantrolene in human diseased cardiomyocytes. Heart Rhythm 14, 412-419. doi: 10.1016/j.hrthm.2016.09.014

Hasenfuss, G., and Pieske, B. (2002). Calcium cycling in congestive heart failure. J. Mol. Cell. Cardiol. 34, 951-969. doi: 10.1006/jmcc.2002.2037

Hegyi, B., Bossuyt, J., Ginsburg, K. S., Mendoza, L. M., Talken, L., Ferrier, W. T., et al. (2018a). Altered repolarization reserve in failing rabbit ventricular myocytes: calcium and $\beta$-adrenergic effects on delayed- and inward-rectifier potassium currents. Circ. Arrhythm. Electrophysiol. 11:e005852. doi: 10.1161/ CIRCEP.117.005852

Hegyi, B., Bossuyt, J., Griffiths, L. G., Shimkunas, R., Coulibaly, Z., Jian, Z., et al. (2018b). Complex electrophysiological remodeling in postinfarction ischemic heart failure. Proc. Natl. Acad. Sci. U.S.A. 115, E3036-E3044. doi: 10.1073/pnas. 1718211115

Heinzel, F. R., MacQuaide, N., Biesmans, L., and Sipido, K. (2011). Dyssynchrony of $\mathrm{Ca}^{+}$release from the sarcoplasmic reticulum as subcellular mechanism of cardiac contractile dysfunction. J. Mol. Cell. Cardiol. 50, 390-400. doi: 10.1016/ j.yjmcc.2010.11.008

Hong, T.-T., Cogswell, R., James, C. A., Kang, G., Pullinger, C. R., Malloy, M. J., et al. (2012). Plasma BIN1 correlates with heart failure and predicts arrhythmia in patients with arrhythmogenic right ventricular cardiomyopathy. Heart Rhythm 9, 961-967. doi: 10.1016/j.hrthm.2012.01.024

Hong, T.-T., Smyth, J. W., Gao, D., Chu, K. Y., Vogan, J. M., Fong, T. S., et al. (2010). BIN1 localizes the L-type calcium channel to cardiac T-tubules. PLoS Biol. 8:e1000312. doi: 10.1371/journal.pbio.1000312

Houser, S. R., and Molkentin, J. D. (2008). Does contractile Ca2 ${ }^{+}$control calcineurin-NFAT signaling and pathological hypertrophy in cardiac myocytes? Sci. Signal. 1:e31. doi: 10.1126/scisignal.125pe31

Hulot, J.-S., Salem, J.-E., Redheuil, A., Collet, J.-P., Varnous, S., Jourdain, P., et al. (2017). Effect of intracoronary administration of AAV1/SERCA2a on ventricular remodelling in patients with advanced systolic heart failure: results from the AGENT-HF randomized phase 2 trial. Eur. J. Heart Fail. 19, 15341541. doi: $10.1002 /$ ejhf. 826

Ibrahim, M., Navaratnarajah, M., Siedlecka, U., Rao, C., Dias, P., Moshkov, A. V., et al. (2012). Mechanical unloading reverses transverse tubule remodelling and normalizes local $\mathrm{Ca}_{2}{ }^{+}$-induced $\mathrm{Ca}_{2}{ }^{+}$release in a rodent model of heart failure. Eur. J. Heart Fail. 14, 571-580. doi: 10.1093/eurjhf/hfs038

Inoue, R., Jian, Z., and Kawarabayashi, Y. (2009). Mechanosensitive TRP channels in cardiovascular pathophysiology. Pharmacol. Ther. 123, 371-385. doi: 10. 1016/j.pharmthera.2009.05.009

Iribe, G., Ward, C. W., Camelliti, P., Bollensdorff, C., Mason, F., Burton, R. A., et al. (2009). Axial stretch of rat single ventricular cardiomyocytes causes an acute and transient increase in $\mathrm{Ca}_{2}{ }^{+}$spark rate. Circ. Res. 104, 787-795. doi: 10.1161/CIRCRESAHA.108.193334

Janse, M. J. (2004). Electrophysiological changes in heart failure and their relationship to arrhythmogenesis. Cardiovasc. Res. 61, 208-217. doi: 10.1016/ j.cardiores.2003.11.018

January, C. T., and Riddle, J. M. (1989). Early afterdepolarizations: mechanism of induction and block. A role for L-type Ca2 ${ }^{+}$current. Circ. Res. 64, 977-990. doi: 10.1161/01.RES.64.5.977 
Jessup, M., Greenberg, B., Mancini, D., Cappola, T., Pauly, D. F., Jaski, B., et al. (2011). Calcium upregulation by percutaneous administration of gene therapy in cardiac disease (CUPID): a phase 2 trial of intracoronary gene therapy of sarcoplasmic reticulum $\mathrm{Ca}_{2}{ }^{+}$-ATPase in patients with advanced heart failure. Circulation 124, 304-313. doi: 10.1161/CIRCULATIONAHA.111.022889

Jian, Z., Han, H., Zhang, T., Puglisi, J., Izu, L. T., Shaw, J. A., et al. (2014). Mechanochemotransduction during cardiomyocyte contraction is mediated by localized nitric oxide signaling. Sci. Signal. 7:ra27. doi: 10.1126/scisignal. 2005046

Johnson, D. M., Heijman, J., Bode, E. F., Greensmith, D. J., van der Linde, H., Abi-Gerges, N., et al. (2013). Diastolic spontaneous calcium release from the sarcoplasmic reticulum increases beat-to-beat variability of repolarization in canine ventricular myocytes after $\beta$-adrenergic stimulation. Circ. Res. 112, 246-256. doi: 10.1161/CIRCRESAHA.112.275735

Johnson, D. M., Heijman, J., Pollard, C. E., Valentin, J.-P., Crijns, H. J. G. M., Abi-Gerges, N., et al. (2010). I(Ks) restricts excessive beat-to-beat variability of repolarization during beta-adrenergic receptor stimulation. J. Mol. Cell. Cardiol. 48, 122-130. doi: 10.1016/j.yjmcc.2009.08.033

Jones, S. P., Greer, J. J. M., van Haperen, R., Duncker, D. J., de Crom, R., and Lefer, D. J. (2003). Endothelial nitric oxide synthase overexpression attenuates congestive heart failure in mice. Proc. Natl. Acad. Sci. U.S.A. 100, 4891-4896. doi: 10.1073/pnas.0837428100

Jost, N., Virág, L., Bitay, M., Takács, J., Lengyel, C., Biliczki, P., et al. (2005). Restricting excessive cardiac action potential and QT prolongation: a vital role for IKs in human ventricular muscle. Circulation 112, 1392-1399. doi: 10.1161/ CIRCULATIONAHA.105.550111

Kashimura, T., Briston, S. J., Trafford, A. W., Napolitano, C., Priori, S. G., Eisner, D. A., et al. (2010). In the RyR2R4496C mouse model of CPVT, $\beta$-adrenergic stimulation induces $\mathrm{Ca}$ waves by increasing SR Ca content and not by decreasing the threshold for Ca waves novelty and significance. Circ. Res. 107, 1483-1489. doi: 10.1161/CIRCRESAHA.110.227744

Kassmann, M., Hansel, A., Leipold, E., Birkenbeil, J., Lu, S.-Q., Hoshi, T., et al. (2008). Oxidation of multiple methionine residues impairs rapid sodium channel inactivation. Pflugers Arch. 456, 1085-1095. doi: 10.1007/s00424-008$0477-6$

Katz, S. D., Khan, T., Zeballos, G. A., Mathew, L., Potharlanka, P., Knecht, M., et al. (1999). Decreased activity of the L-arginine-nitric oxide metabolic pathway in patients with congestive heart failure. Circulation 99, 2113-2117. doi: 10.1161/ 01.CIR.99.16.2113

Kawase, Y., Ly, H. Q., Prunier, F., Lebeche, D., Shi, Y., Jin, H., et al. (2008). Reversal of cardiac dysfunction after long-term expression of SERCA2a by gene transfer in a pre-clinical model of heart failure. J. Am. Coll. Cardiol. 51, 1112-1119. doi: 10.1016/j.jacc.2007.12.014

Kehat, I., and Molkentin, J. D. (2010). Molecular pathways underlying cardiac remodeling during pathophysiologic stimulation. Circulation 122, 2727-2735. doi: 10.1161/CIRCULATIONAHA.110.942268

Khairallah, R. J., Shi, G., Sbrana, F., Prosser, B. L., Borroto, C., Mazaitis, M. J., et al. (2012). Microtubules underlie dysfunction in duchenne muscular dystrophy. Sci. Signal. 5:ra56. doi: 10.1126/scisignal.2002829

Kho, C., Lee, A., and Hajjar, R. J. (2012). Altered sarcoplasmic reticulum calcium cycling-targets for heart failure therapy. Nat. Rev. Cardiol. 9, 717-733. doi: 10.1038/nrcardio.2012.145

Klipp, R. C., Li, N., Wang, Q., Word, T. A., Sibrian-Vazquez, M., Strongin, R. M., et al. (2018). EL20, a potent antiarrhythmic compound, selectively inhibits calmodulin-deficient ryanodine receptor type 2 . Heart Rhythm 15, 578-586. doi: 10.1016/j.hrthm.2017.12.017

Kohlhaas, M., Liu, T., Knopp, A., Zeller, T., Ong, M. F., Böhm, M., et al. (2010). Elevated cytosolic $\mathrm{Na}^{+}$increases mitochondrial formation of reactive oxygen species in failing cardiac myocytes. Circulation 121, 1606-1613. doi: 10.1161/ CIRCULATIONAHA.109.914911

Kokkonen, K., and Kass, D. A. (2017). Nanodomain regulation of cardiac cyclic nucleotide signaling by phosphodiesterases. Annu. Rev. Pharmacol. Toxicol. 57, 455-479. doi: 10.1146/annurev-pharmtox-010716-104756

Koumi, S., Backer, C. L., Arentzen, C. E., and Sato, R. (1995). beta-Adrenergic modulation of the inwardly rectifying potassium channel in isolated human ventricular myocytes. Alteration in channel response to beta-adrenergic stimulation in failing human hearts. J. Clin. Invest. 96, 2870-2881. doi: 10.1172/ JCI118358
Kuwahara, K., Wang, Y., McAnally, J., Richardson, J. A., Bassel-Duby, R., Hill, J. A., et al. (2006). TRPC6 fulfills a calcineurin signaling circuit during pathologic cardiac remodeling. J. Clin. Invest. 116, 3114-3126. doi: 10.1172/JCI27702

Landstrom, A. P., Dobrev, D., and Wehrens, X. H. T. (2017). Calcium signaling and cardiac arrhythmias. Circ. Res. 120, 1969-1993. doi: 10.1161/CIRCRESAHA. 117.310083

Lang, D., Holzem, K., Kang, C., Xiao, M., Hwang, H. J., Ewald, G. A., et al. (2015). Arrhythmogenic remodeling of $\beta 2$ versus $\beta 1$ adrenergic signaling in the human failing heart. Circ. Arrhythm. Electrophysiol. 8, 409-419. doi: 10.1161/CIRCEP. 114.002065

Lang, D., Sato, D., Jiang, Y., Ginsburg, K. S., Ripplinger, C. M., and Bers, D. M. (2017). Calcium-dependent arrhythmogenic foci created by weakly coupled myocytes in the failing heart. Circ. Res. 121, 1379-1391. doi: 10.1161/ CIRCRESAHA.117.312050

Lazzara, R., and Marchi, S. (1989). "Electrophysiologic mechanisms for the generation of arrhythmias with adrenergic stimulation," in Adrenergic System and Ventricular Arrhythmias in Myocardial Infarction, eds J. Brachmann and A. Schömig (Berlin: Springer), 231-238. doi: 10.1007/978-3-642-74317-7_19

Lebek, S., Plößl, A., Baier, M., Mustroph, J., Tarnowski, D., Lücht, C. M., et al. (2018). The novel CaMKII inhibitor GS-680 reduces diastolic SR Ca leak and prevents CaMKII-dependent pro-arrhythmic activity. J. Mol. Cell. Cardiol. 118, 159-168. doi: 10.1016/j.yjmcc.2018.03.020

Lederer, W. J., and Tsien, R. W. (1976). Transient inward current underlying arrhythmogenic effects of cardiotonic steroids in Purkinje fibres. J. Physiol. 263, 73-100. doi: 10.1113/jphysiol.1976.sp011622

Li, G.-R., Lau, C.-P., Ducharme, A., Tardif, J.-C., and Nattel, S. (2002). Transmural action potential and ionic current remodeling in ventricles of failing canine hearts. Am. J. Physiol. Heart Circ. Physiol. 283, H1031-H1041. doi: 10.1152/ ajpheart.00105.2002

Li, H., Lichter, J. G., Seidel, T., Tomaselli, G. F., Bridge, J. H. B., and Sachse, F. B. (2015). Cardiac resynchronization therapy reduces subcellular heterogeneity of ryanodine receptors, T-tubules, and $\mathrm{Ca}^{+}$sparks produced by dyssynchronous heart failure. Circ. Heart Fail. 8, 1105-1114. doi: 10.1161/ CIRCHEARTFAILURE.115.002352

Liang, J., Huang, B., Yuan, G., Chen, Y., Liang, F., Zeng, H., et al. (2017). Stretchactivated channel Piezol is up-regulated in failure heart and cardiomyocyte stimulated by AngII. Am. J. Transl. Res. 9, 2945-2955.

Lindner, M., Brandt, M. C., Sauer, H., Hescheler, J., Böhle, T., and Beuckelmann, D. J. (2002). Calcium sparks in human ventricular cardiomyocytes from patients with terminal heart failure. Cell Calcium 31, 175-182. doi: 10.1054/ ceca. 2002.0272

Liu, M., Liu, H., and Dudley, S. C. (2010). Reactive oxygen species originating from mitochondria regulate the cardiac sodium channel. Circ. Res. 107, 967-974. doi: 10.1161/CIRCRESAHA.110.220673

Liu, N., Colombi, B., Memmi, M., Zissimopoulos, S., Rizzi, N., Negri, S., et al. (2006). Arrhythmogenesis in catecholaminergic polymorphic ventricular tachycardia: insights from a RyR2 R4496C knock-in mouse model. Circ. Res. 99, 292-298. doi: 10.1161/01.RES.0000235869.50747.e1

Lohse, M. J., Engelhardt, S., and Eschenhagen, T. (2003). What is the role of $\beta$-adrenergic signaling in heart failure? Circ. Res. 93, 896-906. doi: 10.1161/01. RES.0000102042.83024.CA

Luo, M., and Anderson, M. E. (2013). Mechanisms of altered Ca2 ${ }^{+}$handling in heart failure. Circ. Res. 113, 690-708. doi: 10.1161/CIRCRESAHA.113.301651

Lyon, A. R., Bannister, M. L., Collins, T., Pearce, E., Sepehripour, A. H., Dubb, S. S., et al. (2011). SERCA2a gene transfer decreases sarcoplasmic reticulum calcium leak and reduces ventricular arrhythmias in a model of chronic heart failure. Circ. Arrhythm. Electrophysiol. 4, 362-372. doi: 10.1161/CIRCEP.110. 961615

Lyon, A. R., MacLeod, K. T., Zhang, Y., Garcia, E., Kanda, G. K., Lab, M. J., et al. (2009). Loss of T-tubules and other changes to surface topography in ventricular myocytes from failing human and rat heart. Proc. Natl. Acad. Sci. U.S.A. 106, 6854-6859. doi: 10.1073/pnas.0809777106

Maier, L. S., and Bers, D. M. (2007). Role of $\mathrm{Ca}^{+} /$/calmodulin-dependent protein kinase (CaMK) in excitation-contraction coupling in the heart. Cardiovasc. Res. 73, 631-640. doi: 10.1016/j.cardiores.2006.11.005

Mak, S., and Newton, G. E. (2004). Redox modulation of the inotropic response to dobutamine is impaired in patients with heart failure. Am. J. Physiol. Heart Circ. Physiol. 286, H789-H795. doi: 10.1152/ajpheart.00633.2003 
Makarewich, C. A., Zhang, H., Davis, J., Correll, R. N., Trappanese, D. M., Hoffman, N. E., et al. (2014). Transient receptor potential channels contribute to pathological structural and functional remodeling after myocardial infarction. Circ. Res. 115, 567-580. doi: 10.1161/CIRCRESAHA.115.303831

Malliani, A., Recordati, G., and Schwartz, P. J. (1973). Nervous activity of afferent cardiac sympathetic fibres with atrial and ventricular endings. J. Physiol. 229, 457-469. doi: 10.1113/jphysiol.1973.sp010147

Maltsev, V. A., Silverman, N., Sabbah, H. N., and Undrovinas, A. I. (2007). Chronic heart failure slows late sodium current in human and canine ventricular myocytes: implications for repolarization variability. Eur. J. Heart Fail. 9, 219-227. doi: 10.1016/j.ejheart.2006.08.007

Manfra, O., Frisk, M., and Louch, W. E. (2017). Regulation of cardiomyocyte T-tubular structure: opportunities for therapy. Curr. Heart Fail. Rep. 14, 167178. doi: 10.1007/s11897-017-0329-9

Marban, E., Robinson, S. W., and Wier, W. G. (1986). Mechanisms of arrhythmogenic delayed and early afterdepolarizations in ferret ventricular muscle. J. Clin. Invest. 78, 1185-1192. doi: 10.1172/JCI112701

Marx, S. O., Reiken, S., Hisamatsu, Y., Jayaraman, T., Burkhoff, D., Rosemblit, N., et al. (2000). PKA phosphorylation dissociates FKBP12.6 from the calcium release channel (ryanodine receptor): defective regulation in failing hearts. Cell 101, 365-376. doi: 10.1016/S0092-8674(00)80847-8

Massion, P. B., Feron, O., Dessy, C., and Balligand, J.-L. (2003). Nitric oxide and cardiac function: ten years after, and continuing. Circ. Res. 93, 388-398. doi: 10.1161/01.RES.0000088351.58510.21

Miura, M., Taguchi, Y., Nagano, T., Sasaki, M., Handoh, T., and Shindoh, C. (2015). Effect of myofilament $\mathrm{Ca}\left(2^{+}\right)$sensitivity on $\mathrm{Ca}\left(2^{+}\right)$wave propagation in rat ventricular muscle. J. Mol. Cell. Cardiol. 84, 162-169. doi: 10.1016/j.yjmcc.2015. 04.027

Miura, M., Wakayama, Y., Endoh, H., Nakano, M., Sugai, Y., Hirose, M., et al. (2008). Spatial non-uniformity of excitation-contraction coupling can enhance arrhythmogenic-delayed afterdepolarizations in rat cardiac muscle. Cardiovasc. Res. 80, 55-61. doi: 10.1093/cvr/cvn162

Moens, A. L., Takimoto, E., Tocchetti, C. G., Chakir, K., Bedja, D., Cormaci, G., et al. (2008). Reversal of cardiac hypertrophy and fibrosis from pressure overload by tetrahydrobiopterin: efficacy of recoupling nitric oxide synthase as a therapeutic strategy. Circulation 117, 2626-2636. doi: 10.1161/CIRCULATIONAHA.107.737031

Morita, H., Suzuki, G., Haddad, W., Mika, Y., Tanhehco, E. J., Sharov, V. G., et al. (2003). Cardiac contractility modulation with nonexcitatory electric signals improves left ventricular function in dogs with chronic heart failure. J. Card. Fail. 9, 69-75. doi: 10.1054/jcaf.2003.8

Morita, N., Sovari, A. A., Xie, Y., Fishbein, M. C., Mandel, W. J., Garfinkel, A., et al. (2009). Increased susceptibility of aged hearts to ventricular fibrillation during oxidative stress. Am. J. Physiol. Heart Circ. Physiol. 297, H1594-H1605. doi: 10.1152/ajpheart.00579.2009

Mukherjee, R., and Spinale, F. G. (1998). L-type calcium channel abundance and function with cardiac hypertrophy and failure: a review. J. Mol. Cell. Cardiol. 30, 1899-1916. doi: 10.1006/jmcc.1998.0755

Muralidharan, P., Szappanos, H. C., Ingley, E., and Hool, L. (2016). Evidence for redox sensing by a human cardiac calcium channel. Sci. Rep. 6:19067. doi: 10.1038/srep19067

Myles, R. C., Wang, L., Bers, D. M., and Ripplinger, C. M. (2015). Decreased inward rectifying $\mathrm{K}^{+}$current and increased ryanodine receptor sensitivity synergistically contribute to sustained focal arrhythmia in the intact rabbit heart. J. Physiol. 593, 1479-1493. doi: 10.1113/jphysiol.2014.279638

Nagy, N., Kormos, A., Kohajda, Z., Szebeni, Á., Szepesi, J., Pollesello, P., et al. (2014). Selective $\mathrm{Na}^{+} / \mathrm{Ca}^{+}$exchanger inhibition prevents $\mathrm{Ca}^{+}$overloadinduced triggered arrhythmias. Br. J. Pharmacol. 171, 5665-5681. doi: 10.1111/ bph. 12867

Nattel, S., Maguy, A., Le Bouter, S., and Yeh, Y.-H. (2007). Arrhythmogenic ionchannel remodeling in the heart: heart failure, myocardial infarction, and atrial fibrillation. Physiol. Rev. 87, 425-456. doi: 10.1152/physrev.00014.2006

Neco, P., Rose, B., Huynh, N., Zhang, R., Bridge, J. H. B., Philipson, K. D., et al. (2010). Sodium-calcium exchange is essential for effective triggering of calcium release in mouse heart. Biophys. J. 99, 755-764. doi: 10.1016/j.bpj.2010.04.071

Nerbonne, J. M., and Kass, R. S. (2005). Molecular physiology of cardiac repolarization. Physiol. Rev. 85, 1205-1253. doi: 10.1152/physrev.00002.2005
Neves, J. S., Leite-Moreira, A. M., Neiva-Sousa, M., Almeida-Coelho, J., CastroFerreira, R., and Leite-Moreira, A. F. (2015). Acute myocardial response to stretch: what we (don't) know. Front. Physiol. 6:408. doi: 10.3389/fphys.2015. 00408

Nikolaev, V. O., Bünemann, M., Schmitteckert, E., Lohse, M. J., and Engelhardt, S. (2006). Cyclic AMP imaging in adult cardiac myocytes reveals far-reaching $\beta 1$-adrenergic but locally confined $\beta 2$-adrenergic receptor-mediated signaling. Circ. Res. 99, 1084-1091. doi: 10.1161/01.RES.0000250046.69918.d5

Nikolaev, V. O., Moshkov, A., Lyon, A. R., Miragoli, M., Novak, P., Paur, H., et al. (2010). Beta2-adrenergic receptor redistribution in heart failure changes cAMP compartmentation. Science 327, 1653-1657. doi: 10.1126/science.1185988

Oestreich, E. A., Malik, S., Goonasekera, S. A., Blaxall, B. C., Kelley, G. G., Dirksen, R. T., et al. (2009). Epac and phospholipase $\mathrm{C} \epsilon$ regulate $\mathrm{Ca}_{2}{ }^{+}$release in the heart by activation of protein kinase $\mathrm{C} \epsilon$ and calcium-calmodulin kinase II. J. Biol. Chem. 284, 1514-1522. doi: 10.1074/jbc.M806994200

Orini, M., Nanda, A., Yates, M., Di Salvo, C., Roberts, N., Lambiase, P. D., et al. (2017). Mechano-electrical feedback in the clinical setting: current perspectives. Prog. Biophys. Mol. Biol. 130, 365-375. doi: 10.1016/j.pbiomolbio.2017.06.001

Pereira, L., Bare, D. J., Galice, S., Shannon, T. R., and Bers, D. M. (2017). $\beta$-Adrenergic induced SR $\mathrm{Ca}^{+}$leak is mediated by an Epac-NOS pathway. J. Mol. Cell. Cardiol. 108, 8-16. doi: 10.1016/j.yjmcc.2017.04.005

Pereira, L., Métrich, M., Fernández-Velasco, M., Lucas, A., Leroy, J., Perrier, R., et al. (2007). The cAMP binding protein Epac modulates $\mathrm{Ca}^{+}{ }^{+}$sparks by a $\mathrm{Ca}^{+} /$calmodulin kinase signalling pathway in rat cardiac myocytes. J. Physiol. 583, 685-694. doi: 10.1113/jphysiol.2007.133066

Petroff, M. G., Kim, S. H., Pepe, S., Dessy, C., Marbán, E., Balligand, J. L., et al. (2001). Endogenous nitric oxide mechanisms mediate the stretch dependence of $\mathrm{Ca}_{2}{ }^{+}$release in cardiomyocytes. Nat. Cell Biol. 3, 867-873. doi: 10.1038/ ncb1001-867

Ponikowski, P., Voors, A. A., Anker, S. D., Bueno, H., Cleland, J. G., Coats, A. J., et al. (2016). 2016 ESC Guidelines for the diagnosis and treatment of acute and chronic heart failure: the Task Force for the diagnosis and treatment of acute and chronic heart failure of the European Society of Cardiology (ESC) Developed with the special contribution of the Heart Failure Association (HFA) of the ESC. Eur. Heart J. 37, 2129-2200. doi: 10.1093/eurheartj/ehw128

Port, J. D., and Bristow, M. R. (2001). Altered beta-adrenergic receptor gene regulation and signaling in chronic heart failure. J. Mol. Cell. Cardiol. 33, 887-905. doi: 10.1006/jmcc.2001.1358

Porter, B., Bishop, M. J., Claridge, S., Behar, J., Sieniewicz, B. J., Webb, J., et al. (2017). Autonomic modulation in patients with heart failure increases beat-tobeat variability of ventricular action potential duration. Front. Physiol. 8:328. doi: 10.3389/fphys.2017.00328

Priori, S. G., and Corr, P. B. (1990). Mechanisms underlying early and delayed afterdepolarizations induced by catecholamines. Am. J. Physiol. 258, H1796H1805. doi: 10.1152/ajpheart.1990.258.6.H1796

Priori, S. G., Mantica, M., Napolitano, C., and Schwartz, P. J. (1990). Early afterdepolarizations induced in vivo by reperfusion of ischemic myocardium. A possible mechanism for reperfusion arrhythmias. Circulation 81, 1911-1920. doi: 10.1161/01.CIR.81.6.1911

Priori, S. G., Mantica, M., and Schwartz, P. J. (1988). Delayed afterdepolarizations elicited in vivo by left stellate ganglion stimulation. Circulation 78, 178-185. doi: 10.1161/01.CIR.78.1.178

Priori, S. G., Napolitano, C., Memmi, M., Colombi, B., Drago, F., Gasparini, M., et al. (2002). Clinical and molecular characterization of patients with catecholaminergic polymorphic ventricular tachycardia. Circulation 106, 6974. doi: 10.1161/01.CIR.0000020013.73106.D8

Prosser, B. L., Ward, C. W., and Lederer, W. J. (2011). X-ROS signaling: rapid mechano-chemo transduction in heart. Science 333, 1440-1445. doi: 10.1126/ science. 1202768

Purohit, A., Rokita, A. G., Guan, X., Chen, B., Koval, O. M., Voigt, N., et al. (2013). Oxidized $\mathrm{Ca}^{+} /$calmodulin-dependent protein kinase II triggers atrial fibrillation. Circulation 128, 1748-1757. doi: 10.1161/CIRCULATIONAHA. 113.003313

Rakhit, A., Maguire, C. T., Wakimoto, H., Gehrmann, J., Li, G. K., Kelly, R. A., et al. (2001). In vivo electrophysiologic studies in endothelial nitric oxide synthase (eNOS)-deficient mice. J. Cardiovasc. Electrophysiol. 12, 1295-1301. doi: 10.1046/j.1540-8167.2001.01295.x 
Ravens, U. (2003). Mechano-electric feedback and arrhythmias. Prog. Biophys. Mol. Biol. 82, 255-266. doi: 10.1016/S0079-6107(03)00026-9

Sag, C. M., Santos, C. X., and Shah, A. M. (2014). Redox regulation of cardiac hypertrophy. J. Mol. Cell. Cardiol. 73, 103-111. doi: 10.1016/j.yjmcc.2014.02. 002

Sag, C. M., Wadsack, D. P., Khabbazzadeh, S., Abesser, M., Grefe, C., Neumann, K., et al. (2009). Calcium/calmodulin-dependent protein kinase II contributes to cardiac arrhythmogenesis in heart failure. Circ. Heart Fail. 2, 664-675. doi: 10.1161/CIRCHEARTFAILURE.109.865279

Sag, C. M., Wagner, S., and Maier, L. S. (2013). Role of oxidants on calcium and sodium movement in healthy and diseased cardiac myocytes. Free Radic. Biol. Med. 63, 338-349. doi: 10.1016/j.freeradbiomed.2013.05.035

Sagawa, K., Lie, R. K., and Schaefer, J. (1990). Translation of Otto frank's paper "Die Grundform des arteriellen Pulses" zeitschrift für biologie 37: 483-526 (1899). J. Mol. Cell. Cardiol. 22, 253-254. doi: 10.1016/0022-2828(90)91459-K

Saini, A., Kannabhiran, M., Reddy, P., Gopinathannair, R., Olshansky, B., and Dominic, P. (2016). Cardiac resynchronization therapy may be antiarrhythmic particularly in responders: a systematic review and meta-analysis. JACC Clin. Electrophysiol. 2, 307-316. doi: 10.1016/j.jacep.2015.10.007

Sánchez, G., Pedrozo, Z., Domenech, R. J., Hidalgo, C., and Donoso, P. (2005). Tachycardia increases NADPH oxidase activity and RyR2 S-glutathionylation in ventricular muscle. J. Mol. Cell. Cardiol. 39, 982-991. doi: 10.1016/j.yjmcc. 2005.08.010

Sanchez-Alonso, J. L., Bhargava, A., O’Hara, T., Glukhov, A. V., Schobesberger, S., Bhogal, N., et al. (2016). Microdomain-specific modulation of L-type calcium channels leads to triggered ventricular arrhythmia in heart failurenovelty and significance. Circ. Res. 119, 944-955. doi: 10.1161/CIRCRESAHA.116.308698

Santangeli, P., Rame, J. E., Birati, E. Y., and Marchlinski, F. E. (2017). Management of ventricular arrhythmias in patients with advanced heart failure. J. Am. Coll. Cardiol. 69, 1842-1860. doi: 10.1016/j.jacc.2017.01.047

Sato, D., Xie, L.-H., Sovari, A. A., Tran, D. X., Morita, N., Xie, F., et al. (2009). Synchronization of chaotic early afterdepolarizations in the genesis of cardiac arrhythmias. Proc. Natl. Acad. Sci. U.S.A. 106, 2983-2988. doi: 10.1073/pnas. 0809148106

Saxon, L. A., Bristow, M. R., Boehmer, J., Krueger, S., Kass, D. A., De Marco, T., et al. (2006). Predictors of sudden cardiac death and appropriate shock in the comparison of medical therapy, pacing, and defibrillation in heart failure (COMPANION) trial. Circulation 114, 2766-2772. doi: 10.1161/ CIRCULATIONAHA.106.642892

Schillinger, W., Fiolet, J. W., Schlotthauer, K., and Hasenfuss, G. (2003). Relevance of $\mathrm{Na}^{+}-\mathrm{Ca}_{2}^{+}$exchange in heart failure. Cardiovasc. Res. 57, 921-933. doi: 10.1016/S0008-6363(02)00826-X

Schobesberger, S., Wright, P., Tokar, S., Bhargava, A., Mansfield, C., Glukhov, A. V., et al. (2017). T-tubule remodelling disturbs localized $\beta 2$-adrenergic signalling in rat ventricular myocytes during the progression of heart failure. Cardiovasc. Res. 113, 770-782. doi: 10.1093/cvr/cvx074

Schönleitner, P., Schotten, U., and Antoons, G. (2017). Mechanosensitivity of microdomain calcium signalling in the heart. Prog. Biophys. Mol. Biol. 130, 288-301. doi: 10.1016/j.pbiomolbio.2017.06.013

Schröder, F., Handrock, R., Beuckelmann, D. J., Hirt, S., Hullin, R., Priebe, L., et al. (1998). Increased availability and open probability of single L-type calcium channels from failing compared with nonfailing human ventricle. Circulation 98, 969-976. doi: 10.1161/01.CIR.98.10.969

Scriven, D. R., and Moore, E. D. (2013). $\mathrm{Ca}_{2}^{+}$channel and $\mathrm{Na}^{+} / \mathrm{Ca}^{2}+$ exchange localization in cardiac myocytes. J. Mol. Cell. Cardiol. 58, 22-31. doi: 10.1016/j. yjmcc.2012.11.022

Seo, K., Rainer, P. P., Lee, D.-I., Hao, S., Bedja, D., Birnbaumer, L., et al. (2014). Hyperactive adverse mechanical stress responses in dystrophic heart are coupled to transient receptor potential canonical 6 and blocked by cGMP-protein kinase G modulation. Circ. Res. 114, 823-832. doi: 10.1161/ CIRCRESAHA.114.302614

Sham, J. S. (1997). $\mathrm{Ca}^{+}$release-induced inactivation of $\mathrm{Ca}^{+}{ }^{+}$current in rat ventricular myocytes: evidence for local $\mathrm{Ca}_{2}{ }^{+}$signalling. J. Physiol. 500(Pt 2), 285-295.

Sham, J. S., Cleemann, L., and Morad, M. (1995). Functional coupling of $\mathrm{Ca}^{+}$ channels and ryanodine receptors in cardiac myocytes. Proc. Natl. Acad. Sci. U.S.A. 92, 121-125. doi: 10.1073/pnas.92.1.121
Sharma, V. K., Ramesh, V., Franzini-Armstrong, C., and Sheu, S.-S. (2000). Transport of $\mathrm{Ca}_{2}^{+}$from sarcoplasmic reticulum to mitochondria in rat ventricular myocytes. J. Bioenerg. Biomembr. 32, 97-104. doi: 10.1023/A: 1005520714221

Shugg, T., Johnson, D. E., Shao, M., Lai, X., Witzmann, F., Cummins, T. R., et al. (2018). Calcium/calmodulin-dependent protein kinase II regulation of IKs during sustained $\beta$-adrenergic receptor stimulation. Heart Rhythm 15, 895-904. doi: 10.1016/j.hrthm.2018.01.024

Simon, J. N., Duglan, D., Casadei, B., and Carnicer, R. (2014). Nitric oxide synthase regulation of cardiac excitation-contraction coupling in health and disease. J. Mol. Cell. Cardiol. 73, 80-91. doi: 10.1016/j.yjmcc.2014.03.004

Sipido, K. R., Callewaert, G., and Carmeliet, E. (1995). Inhibition and rapid recovery of $\mathrm{Ca}_{2}{ }^{+}$current during $\mathrm{Ca}_{2}{ }^{+}$release from sarcoplasmic reticulum in guinea pig ventricular myocytes. Circ. Res. 76, 102-109. doi: 10.1161/01.RES.76. 1.102

Sipido, K. R., Stankovicova, T., Vanhaecke, J., Flameng, W., and Verdonckc, F. (1998). A critical role for $\mathrm{L}-$ type $\mathrm{Ca}_{2}{ }^{+}$current in the regulation of $\mathrm{Ca}_{2}{ }^{+}$release from the sarcoplasmic reticulum in human ventricular myocytes from dilated cardiomyopathy. Ann. N. Y. Acad. Sci. 853, 353-356. doi: 10.1111/j.1749-6632. 1998.tb08298.x

Sipido, K. R., Volders, P. G. A., Vos, M. A., and Verdonck, F. (2002). Altered Na/Ca exchange activity in cardiac hypertrophy and heart failure: a new target for therapy? Cardiovasc. Res. 53, 782-805. doi: 10.1016/S0008-6363(01)00470-9

Song, L.-S., Sobie, E. A., McCulle, S., Lederer, W. J., Balke, C. W., and Cheng, H. (2006). Orphaned ryanodine receptors in the failing heart. Proc. Natl. Acad. Sci. U.S.A. 103, 4305-4310. doi: 10.1073/pnas. 0509324103

Song, Y., Shryock, J. C., Wagner, S., Maier, L. S., and Belardinelli, L. (2006). Blocking late sodium current reduces hydrogen peroxide-induced arrhythmogenic activity and contractile dysfunction. J. Pharmacol. Exp. Ther. 318, 214-222. doi: 10.1124/jpet.106.101832

Song, Y.-H., Cho, H., Ryu, S.-Y., Yoon, J.-Y., Park, S.-H., Noh, C.-I., et al. (2010). L-type $\mathrm{Ca}_{2}{ }^{+}$channel facilitation mediated by $\mathrm{H}_{2} \mathrm{O}_{2}$-induced activation of CaMKII in rat ventricular myocytes. J. Mol. Cell. Cardiol. 48, 773-780. doi: 10.1016/j.yjmcc.2009.10.020

Sossalla, S., Fluschnik, N., Schotola, H., Ort, K. R., Neef, S., Schulte, T., et al. (2010). Inhibition of elevated $\mathrm{Ca}_{2}+/$ calmodulin-dependent protein kinase II improves contractility in human failing myocardium. Circ. Res. 107, 1150-1161. doi: 10.1161/CIRCRESAHA.110.220418

Sukharev, S. I., Blount, P., Martinac, B., Blattner, F. R., and Kung, C. (1994). A large-conductance mechanosensitive channel in E. coli encoded by mscL alone. Nature 368, 265-268. doi: 10.1038/368265a0

Swaminathan, P. D., Purohit, A., Hund, T. J., and Anderson, M. E. (2012). Calmodulin-dependent protein kinase II: linking heart failure and arrhythmias. Circ. Res. 110, 1661-1677. doi: 10.1161/CIRCRESAHA.111.243956

Tavi, P., Laine, M., Weckström, M., and Ruskoaho, H. (2001). Cardiac mechanotransduction: from sensing to disease and treatment. Trends Pharmacol. Sci. 22, 254-260. doi: 10.1016/S0165-6147(00)01679-5

Terracciano, C. M., Hardy, J., Birks, E. J., Khaghani, A., Banner, N. R., and Yacoub, M. H. (2004). Clinical recovery from end-stage heart failure using leftventricular assist device and pharmacological therapy correlates with increased sarcoplasmic reticulum calcium content but not with regression of cellular hypertrophy. Circulation 109, 2263-2265. doi: 10.1161/01.CIR.0000129233. 51320.92

Tomaselli, G. F., and Marbán, E. (1999). Electrophysiological remodeling in hypertrophy and heart failure. Cardiovasc. Res. 42, 270-283. doi: 10.1016/ S0008-6363(99)00017-6

Toschi-Dias, E., Rondon, M. U. P. B., Cogliati, C., Paolocci, N., Tobaldini, E., and Montano, N. (2017). Contribution of autonomic reflexes to the hyperadrenergic state in heart failure. Front. Neurosci. 11:162. doi: 10.3389/fnins.2017.00162

Tsuji, Y., Opthof, T., Kamiya, K., Yasui, K., Liu, W., Lu, Z., et al. (2000). Pacinginduced heart failure causes a reduction of delayed rectifier potassium currents along with decreases in calcium and transient outward currents in rabbit ventricle. Cardiovasc. Res. 48, 300-309. doi: 10.1016/S0008-6363(00)00180-2

Ungerer, M., Böhm, M., Elce, J. S., Erdmann, E., and Lohse, M. J. (1993). Altered expression of beta-adrenergic receptor kinase and beta 1-adrenergic receptors in the failing human heart. Circulation 87, 454-463. doi: 10.1161/01.CIR.87. 2.454 
van Oort, R. J., McCauley, M. D., Dixit, S. S., Pereira, L., Yang, Y., Respress, J. L., et al. (2010). Ryanodine receptor phosphorylation by CaMKII promotes lifethreatening ventricular arrhythmias in mice with heart failure. Circulation 122, 2669-2679. doi: 10.1161/CIRCULATIONAHA.110.982298

Varró, A., Baláti, B., Iost, N., Takács, J., Virág, L., Lathrop, D. A., et al. (2000). The role of the delayed rectifier component IKs in dog ventricular muscle and Purkinje fibre repolarization. J. Physiol. 523, 67-81. doi: 10.1111/j.1469-7793. 2000.00067.x

Vegh, A., Szekeres, L., and Parratt, J. (1992). Preconditioning of the ischaemic myocardium; involvement of the L-arginine nitric oxide pathway. $\mathrm{Br} . \mathrm{J}$. Pharmacol. 107, 648-652. doi: 10.1111/j.1476-5381.1992.tb14501.x

Veldkamp, M. W., van Ginneken, A. C., Opthof, T., and Bouman, L. N. (1995). Delayed rectifier channels in human ventricular myocytes. Circulation 92, 3497-3504. doi: 10.1161/01.CIR.92.12.3497

Veldkamp, M. W., Verkerk, A. O., van Ginneken, A. C. G., Baartscheer, A., Schumacher, C., de Jonge, N., et al. (2001). Norepinephrine induces action potential prolongation and early afterdepolarizations in ventricular myocytes isolated from human end-stage failing hearts. Eur. Heart J. 22, 955-963. doi: 10.1053/euhj.2000.2499

Venetucci, L. A., Trafford, A. W., O’Neill, S. C., and Eisner, D. A. (2008). The sarcoplasmic reticulum and arrhythmogenic calcium release. Cardiovasc. Res. 77, 285-292. doi: 10.1093/cvr/cvm009

Verkerk, A. O., Veldkamp, M. W., Baartscheer, A., Schumacher, C. A., Klöpping, C., van Ginneken, A. C. G., et al. (2001). Ionic mechanism of delayed afterdepolarizations in ventricular cells isolated from human end-stage failing hearts. Circulation 104, 2728-2733. doi: 10.1161/hc4701.099577

Vermeulen, J. T., Mcguire, M. A., Opthof, T., Coronel, R., de Bakker, J. M., Klöpping, C., et al. (1994). Triggered activity and automaticity in ventricular trabeculae of failing human and rabbit hearts. Cardiovasc. Res. 28, 1547-1554. doi: $10.1093 / \mathrm{cvr} / 28.10 .1547$

Viatchenko-Karpinski, S., Kornyeyev, D., El-Bizri, N., Budas, G., Fan, P., Jiang, Z., et al. (2014). Intracellular $\mathrm{Na}^{+}$overload causes oxidation of CaMKII and leads to $\mathrm{Ca}^{+}$mishandling in isolated ventricular myocytes. J. Mol. Cell. Cardiol. 76, 247-256. doi: 10.1016/j.yjmcc.2014.09.009

Vielma, A. Z., León, L., Fernández, I. C., González, D. R., and Boric, M. P. (2016). Nitric oxide synthase 1 modulates basal and $\beta$-adrenergic-stimulated contractility by rapid and reversible redox-dependent S-nitrosylation of the heart. PLoS One 11:e0160813. doi: 10.1371/journal.pone.0160813

Volders, P. G., Kulcśar, A., Vos, M. A., Sipido, K. R., Wellens, H. J., Lazzara, R., et al. (1997). Similarities between early and delayed afterdepolarizations induced by isoproterenol in canine ventricular myocytes. Cardiovasc. Res. 34, 348-359. doi: 10.1016/S0008-6363(96)00270-2

Volders, P. G., Stengl, M., van Opstal, J. M., Gerlach, U., Spätjens, R. L., Beekman, J. D., et al. (2003). Probing the contribution of IKs to canine ventricular repolarization: key role for beta-adrenergic receptor stimulation. Circulation 107, 2753-2760. doi: 10.1161/01.CIR.0000068344.54010.B3

Volders, P. G., Vos, M. A., Szabo, B., Sipido, K. R., de Groot, S. H., Gorgels, A. P., et al. (2000). Progress in the understanding of cardiac early afterdepolarizations and torsades de pointes: time to revise current concepts. Cardiovasc. Res. 46, 376-392. doi: 10.1016/S0008-6363(00)00022-5

von Anrep, G. (1912). On the part played by the suprarenals in the normal vascular reactions of the body. J. Physiol. 45, 307-317. doi: 10.1113/jphysiol. 1912.sp001553

Waagstein, F., Bristow, M. R., Swedberg, K., Camerini, F., Fowler, M. B., Silver, M. A., et al. (1993). Beneficial effects of metoprolol in idiopathic dilated cardiomyopathy. Metoprolol in Dilated Cardiomyopathy (MDC) Trial Study Group. Lancet 342, 1441-1446. doi: 10.1016/0140-6736(93)92930-R

Wagner, S., Dybkova, N., Rasenack, E. C. L., Jacobshagen, C., Fabritz, L., Kirchhof, P., et al. (2006). Ca2 $2^{+} /$calmodulin-dependent protein kinase II regulates cardiac $\mathrm{Na}^{+}$channels. J. Clin. Invest. 116, 3127-3138. doi: 10.1172/ JCI26620

Wagner, S., Rokita, A. G., Anderson, M. E., and Maier, L. S. (2013). Redox regulation of sodium and calcium handling. Antioxid. Redox Signal. 18, 10631077. doi: 10.1089/ars.2012.4818

Wagner, S., Ruff, H. M., Weber, S. L., Bellmann, S., Sowa, T., Schulte, T., et al. (2011). Reactive oxygen species-activated $\mathrm{Ca} /$ calmodulin kinase II $\delta$ is required for late $\mathrm{I}(\mathrm{Na})$ augmentation leading to cellular $\mathrm{Na}$ and $\mathrm{Ca}$ overload. Circ. Res. 108, 555-565. doi: 10.1161/CIRCRESAHA.110.221911
Wang, H., Kohr, M. J., Wheeler, D. G., and Ziolo, M. T. (2008). Endothelial nitric oxide synthase decreases beta-adrenergic responsiveness via inhibition of the L-type Ca2 ${ }^{+}$current. Am. J. Physiol. Heart Circ. Physiol. 294, H1473-H1480. doi: 10.1152/ajpheart.01249.2007

Wang, H., Viatchenko-Karpinski, S., Sun, J., Györke, I., Benkusky, N. A., Kohr, M. J., et al. (2010). Regulation of myocyte contraction via neuronal nitric oxide synthase: role of ryanodine receptor S-nitrosylation. J. Physiol. 588, 2905-2917. doi: 10.1113/jphysiol.2010.192617

Wang, J., Ma, Y., Sachs, F., Li, J., and Suchyna, T. M. (2016). GsMTx4$\mathrm{D}$ is a cardioprotectant against myocardial infarction during ischemia and reperfusion. J. Mol. Cell. Cardiol. 98, 83-94. doi: 10.1016/j.yjmcc.2016. 07.005

Wang, W., and Zucker, I. H. (1996). Cardiac sympathetic afferent reflex in dogs with congestive heart failure. Am. J. Physiol. 271, R751-R756. doi: 10.1152/ ajpregu.1996.271.3.R751

Wehrens, X. H., Lehnart, S. E., Reiken, S. R., and Marks, A. R. (2004). Ca2 ${ }^{+}$ /calmodulin-dependent protein kinase II phosphorylation regulates the cardiac ryanodine receptor. Circ. Res. 94, e61-e70. doi: 10.1161/01.RES.0000125626. 33738.E2

Wei, X.-H., Yu, S.-D., Ren, L., Huang, S.-H., Yang, Q.-M., Wang, P., et al. (2017). Inhibition of late sodium current suppresses calcium-related ventricular arrhythmias by reducing the phosphorylation of CaMK-II and sodium channel expressions. Sci. Rep. 7:981. doi: 10.1038/s41598-017-0 1056-0

Westenbrink, B. D., Edwards, A. G., McCulloch, A. D., and Brown, J. H. (2013). The promise of CaMKII inhibition for heart disease: preventing heart failure and arrhythmias. Expert Opin. Ther. Targets 17, 889-903. doi: 10.1517/14728222. 2013.809064

White, E. (2006). Mechanosensitive channels: therapeutic targets in the myocardium? Curr. Pharm. Des. 12, 3645-3663.

Wit, A. L., and Rosen, M. R. (1983). Pathophysiologic mechanisms of cardiac arrhythmias. Am. Heart J. 106, 798-811. doi: 10.1016/0002-8703(83)9 0003-0

Wright, P. T., Nikolaev, V. O., O’Hara, T., Diakonov, I., Bhargava, A., Tokar, S., et al. (2014). Caveolin-3 regulates compartmentation of cardiomyocyte beta2adrenergic receptor-mediated cAMP signaling. J. Mol. Cell. Cardiol. 67, 38-48. doi: 10.1016/j.yjmcc.2013.12.003

Xiao, B., Sutherland, C., Walsh, M. P., and Chen, S. R. W. (2004). Protein kinase A phosphorylation at serine- 2808 of the cardiac $\mathrm{Ca}_{2}^{+}$-release channel (ryanodine receptor) does not dissociate 12.6-kDa FK506-binding protein (FKBP12.6). Circ. Res. 94, 487-495. doi: 10.1161/01.RES.0000115945.89 741.22

Xie, L.-H., Chen, F., Karagueuzian, H. S., and Weiss, J. N. (2009). Oxidative-stressinduced afterdepolarizations and calmodulin kinase II signaling. Circ. Res. 104, 79-86. doi: 10.1161/CIRCRESAHA.108.183475

Xie, Y., Sato, D., Garfinkel, A., Qu, Z., and Weiss, J. N. (2010). So little source, so much sink: requirements for afterdepolarizations to propagate in tissue. Biophys. J. 99, 1408-1415. doi: 10.1016/j.bpj.2010.06.042

Xu, K. Y., Huso, D. L., Dawson, T. M., Bredt, D. S., and Becker, L. C. (1999). Nitric oxide synthase in cardiac sarcoplasmic reticulum. Proc. Natl. Acad. Sci. U.S.A. 96, 657-662. doi: 10.1073/pnas.96.2.657

Xu, L., Eu, J. P., Meissner, G., and Stamler, J. S. (1998). Activation of the cardiac calcium release channel (ryanodine receptor) by poly-S-nitrosylation. Science 279, 234-237. doi: 10.1126/science.279.5348.234

Yamada, K. A., and Corr, P. B. (1992). Effects of $\beta$-adrenergic receptor activation on intracellular calcium and membrane potential in adult cardiac myocytes. J. Cardiovasc. Electrophysiol. 3, 209-224. doi: 10.1111/j.1540-8167. 1992.tb00968.x

Yamaguchi, Y., Iribe, G., Nishida, M., and Naruse, K. (2017). Role of TRPC3 and TRPC6 channels in the myocardial response to stretch: linking physiology and pathophysiology. Prog. Biophys. Mol. Biol. 130, 264-272. doi: 10.1016/j. pbiomolbio.2017.06.010

Yan, Y., Liu, J., Wei, C., Li, K., Xie, W., Wang, Y., et al. (2008). Bidirectional regulation of $\mathrm{Ca}_{2}{ }^{+}$sparks by mitochondria-derived reactive oxygen species in cardiac myocytes. Cardiovasc. Res. 77, 432-441. doi: 10.1093/cvr/ cvm047

Zahradníková, A., Minarovic, I., Venema, R. C., and Mészáros, L. G. (1997). Inactivation of the cardiac ryanodine receptor calcium release channel 
by nitric oxide. Cell Calcium 22, 447-454. doi: 10.1016/\$0143-4160(97) 90072-5

Zeng, J., and Rudy, Y. (1995). Early afterdepolarizations in cardiac myocytes: mechanism and rate dependence. Biophys. J. 68, 949-964. doi: 10.1016/S00063495(95)80271-7

Zhang, H., Gomez, A. M., Wang, X., Yan, Y., Zheng, M., and Cheng, H. (2013). ROS regulation of microdomain $\mathrm{Ca}_{2}{ }^{+}$signalling at the dyads. Cardiovasc. Res. 98, 248-258. doi: $10.1093 / \mathrm{cvr} / \mathrm{cvt} 050$

Zhang, M., Perino, A., Ghigo, A., Hirsch, E., and Shah, A. M. (2013). NADPH oxidases in heart failure: poachers or gamekeepers? Antioxid. Redox Signal. 18, 1024-1041. doi: 10.1089/ars.2012.4550

Zima, A. V., and Blatter, L. A. (2006). Redox regulation of cardiac calcium channels and transporters. Cardiovasc. Res. 71, 310-321. doi: 10.1016/j.cardiores.2006. 02.019
Zygmunt, A. C., Goodrow, R. J., and Weigel, C. M. (1998). INaCa and $\mathrm{ICl}(\mathrm{Ca})$ contribute to isoproterenol-induced delayed after depolarizations in midmyocardial cells. Am. J. Physiol. 275, H1979-H1992.

Conflict of Interest Statement: The authors declare that the research was conducted in the absence of any commercial or financial relationships that could be construed as a potential conflict of interest.

Copyright $\odot 2018$ Johnson and Antoons. This is an open-access article distributed under the terms of the Creative Commons Attribution License (CC BY). The use, distribution or reproduction in other forums is permitted, provided the original author(s) and the copyright owner(s) are credited and that the original publication in this journal is cited, in accordance with accepted academic practice. No use, distribution or reproduction is permitted which does not comply with these terms. 